\title{
The Biological and Ethical Basis of the Use of Human Embryonic Stem Cells for In Vitro Test Systems or Cell Therapy
}

Marcel Leist ${ }^{1}$, Susanne Bremer ${ }^{2}$, Patrik Brundin ${ }^{3}$, Jürgen Hescheler ${ }^{4}$, Agnete Kirkeby ${ }^{5,6}$, Karl-Heinz Krause ${ }^{7}$, Peter Pörzgen ${ }^{8}$, Michel Pucéat ${ }^{9}$, Mathias Schmidt ${ }^{10}$, André Schrattenholz ${ }^{11}$, Naomi B. Zak ${ }^{12}$, Hannes Hentze ${ }^{13}$

${ }^{1}$ Doerenkamp-Zbinden Chair for Alternative in vitro Methods, University of Konstanz, Germany; ${ }^{2}$ Institute for Consumer Health and Protection, EU Joint Research Center, Ispra, Italy; ${ }^{3}$ Wallenberg Neuroscience Center, Lund University, S-22184 Lund, Sweden; ${ }^{4}$ Institute of Neurophysiology, University of Cologne, Germany; ${ }^{5}$ Memorial Sloan Kettering Cancer Center, Developmental Biology, New York, USA; ${ }^{6}$ H. Lundbeck A/S, Valby, Denmark; ${ }^{7}$ Centre Medical Universitaire 1, Geneva, Switzerland; ${ }^{8}$ Hawaii Pacific University, Kaneohe, USA; ${ }^{9}$ INSERM/Université-EvryUMR-861, Evry, France; ${ }^{10}$ Nycomed GmbH, Konstanz, Germany;

${ }^{11}$ Proteosys AG, Mainz, Germany; ${ }^{12}$ CellCure Neurosciences Ltd., Jerusalem, Israel; ${ }^{13}$ S*BIO Pte Ltd, Singapore

\section{Summary}

Human embryonic stem cells ( $h E S C$ ) are now routinely cultured in many laboratories, and differentiation protocols are available to generate a large variety of cell types. In an ongoing ethical debate opinions of different groups are based on varying sets of religious, historical, cultural and scientific arguments as well as on widely differing levels of general information. We here give an overview of the biological background for non-specialists, and address all issues of the current stem cell debate that are of concern in different cultures and states. Thirty-five chapters address embryo definition, potential killing and the beginning of human life, in addition to matters of human dignity, patenting, commercialisation, and potential alternatives for the future, such as induced pluripotent (reprogrammed) stem cells. All arguments are compiled in a synopsis, and compromise solutions, e.g. for the definition of the beginning of personhood and for assigning dignity to embryos, are suggested. Until recently, the major application of hESC was thought to be transplantation of cells derived from hESC for therapeutic use. We discuss here that the most likely immediate uses will rather be in vitro test systems and disease models. Major and minor pharmaceutical companies have entered this field, and the European Union is sponsoring academic research into hESC-based innovative test systems. This development is supported by new testing strategies in Europe and the USA focussing on human cell-based in vitro systems for safety evaluations, and shifting the focus of toxicology away from classical animal experiments towards a more mechanistic understanding.
Zusammenfassung: Die biologische und ethische Grundlage für die Anwendung embryonaler Stammzellen für in vitro Testsysteme und Zelltherapie

Humane embryonale Stammzellen (hESC) werden jetzt routinemäßig in vielen Labors kultiviert, und Differenzierungsprotokolle wurden entwickelt, um eine breite Palette unterschiedlicher Zelltypen herzustellen. In der derzeitigen ethischen Diskussion stützen sich die Meinungen der verschiedenen Parteien auf religiöse, historische, kulturelle und wissenschaftliche Argumente. Ebenfalls tragen unterschiedliche Informationsniveaus zur Bildung unterschiedlicher Meinungen bei. Wir geben hier eine Übersicht für den Laien über den biologischen Hintergrund und sprechen alle Aspekte der gegenwärtigen Stammzelldebatte an, die derzeit die Menschen in verschiedenen Ländern und Kulturen bewegen. Fünfunddreißig Unterkapitel beschäftigen sich mit der Embryodefinition, dem Tötungsaspekt und der Definition des Anfangs des Lebens, aber auch mit Aspekten der Menschenwürde, der Patentierung und Kommerzialisierung von Leben und möglichen Alternativen für die Zukunft, wie induziert pluripotenten (reprogrammierten) Stammzellen. Alle Argumente wurden synoptisch zusammengestellt. Kompromisslösungen z.B. für die Definition des Anfangs der Menschwerdung und für den Status der Menschenwürde von Embryos werden präsentiert. Bis vor kurzem ging man davon aus, dass die Hauptanwendung von hESC bei der Transplantation von Zellen, die aus hESC hergestellt würden, läge. Wir diskutieren hier, dass die wahrscheinlichsten Anwendungen eher im Bereich der in vitro Testsysteme und Krankheitsmodelle liegen werden. Größere und kleinere pharmazeutische Unternehmen sind auf dieses Gebiet eingestiegen, und die Europäische Union fördert akademische Forschung an innovativen Testsystemen, die auf hESC beruhen. Diese Aktivitäten entsprechen Entwicklungen auf beiden Seiten des Atlantiks, die darauf abzielen, mehr in vitro Testsysteme für die Evaluierung von Sicherheitskriterien zu benutzen, die auf menschlichen Zellen aufbauen, und darauf hinzielen, den Fokus der Toxikologie weg von klassischen Tierexperimenten und hin zu einem mechanistischen Verständnis zu richten.

Keywords: in vitro toxicology, human embryonic stem cells, stem cell ethics, iPs cells 


\section{Introduction and background}

Human embryonic stem cells (hESC) are presently being cultured in many laboratories, and differentiation protocols are available for a large variety of cell types. The most immediate use of these cells may not be therapeutic applications, but more immediately, the design of test systems for toxicological and pharmacological research (UKTI, 2005; Bremer and Hartung, 2004; Vogel, 2005). The use of such human-based test systems would contribute to a bottom-up test strategy for new chemicals, where initially the mode of action is explored, and animal experiments are only used as a last resort and in special situations (Leist et al. 2008a). One obstacle to the broad use of hESC for experimental test systems are ethical issues that have different legal implications in different countries (MBBNET, 2008).

What are embryonic stem cells? Before entering a bioethical debate it is important to create a common platform of biological facts important for such a debate. We will first take a look at natural conception and embryo development as basis for the overall understanding of the technology (Fig. 1A). After fertilization of the oocyte ("egg") in the oviduct by a sperm, a zygote is formed. This cell, which contains genetic information from two parental gametes (i.e. the oocyte and sperm) starts dividing while migrating down the oviduct, and gives rise to a tiny (less than $0.1 \mathrm{~mm}$ ), blackberry-shaped, compact cell clump termed the morula, which eventually enters the uterus at around day 4. By day 5 , a cavity is formed in the "ball" and the resulting structure of embryonic cells is now termed early blastocyst. The blastocyst is initially surrounded by a translucent structure (the zona pellucida) that protects it and prevents it from attaching to incorrect structures. In the uterus, the blastocyst begins to form different cell types - the outer cells (40-80), which will later become the placenta, and the inner cell mass (ICM) of about 20-45 cells which will later develop the embryo (Hardy et al., 1989). Eventually it "hatches" i.e. it breaks out of the zona pellucida and attaches to the wall of the uterus. This process of "implantation" of the late blastocyst occurs around day 9 post-fertilization and represents the first physical connection between the early embryo and the fertilized woman. This step, also termed "nidation", is crucial for the development of embryo polarity (body axes/up and down-definition). Finally, at day 12-14, a dramatic morphological restructuring occurs when the embryonic cells form a double-layered structure - the gastrula. This is the start of primitive tissue formation (primitive streak) in the embryo proper (the real embryo). At day 14, therefore, pregnancy is established, the embryo has a close connection to the womb, it has developed polarity as well as "inside" and "outside" directionality, and, importantly, the three germ layers (primordial tissues) begin to form early organs such as the primitive gut and neural system. In parallel the placenta forms from formerly external cells of the blastocyst.

Couples facing problems in conceiving naturally (in some countries also women that can get anonymous sperm) now have the option to increase their chances of pregnancy by undergoing an in vitro fertilization (IVF) procedure. This process differs from a naturally-occurring pregnancy only in the initiation phase where sperm and oocyte meet (Fig. 1B). Oocytes are harvested from the woman, and this process is facilitated by ovarian stimulation with hormones. Then they are fertilized with a sperm sample from the potential father to form zygotes. Typically, 10-15 early pre-implantation embryos are generated in such a process and propagated in vitro up to the blastocyst stage (day 5). In some countries (e.g. Germany), national regulations forbid selection of the embryo after nuclear fusion and preclude the cultivation of more than three embryos at a time (Zollner et al., 2003). After positive selection of the best blastocysts, 1-3 (depending on the country) are re-implanted directly into the uterus, where they have the chance to attach to the uterine wall and form an embryo just as it occurs in a natural conception. IVF procedures result in a successful pregnancy in about $15-25 \%$ of the procedures. If the first attempt is unsuccessful, a second and third round of re-implantation of blastocysts may be initiated, since the initially superfluous blastocysts are typically cryopreserved, i.e. stored in a liquid nitrogen tank where they can be maintained for several years. It is not known when a blastocyst under conditions of cryopreservation loses its potential to form an embryo. Albeit one case study reported a successful pregnancy after implantation of a blastocyst stored for 12 years (Revel et al., 2004), it is generally observed that the quality is strongly declining after 5-10 years. Many supernumerary blastocysts accumulate in fertility clinics and will be ultimately destroyed. It is estimated that 400,000 fertilized oocytes were stored in 450 fertility clinics in the USA alone in 2003. Tens of thousands are also frozen in Germany, Switzerland, Austria, the UK and many European and Asian countries. Thus, it is reasonable to assume that by now over one million pre-implantation embryos are stored in the USA and elsewhere. A very small minority of these (less than $1 \%$ ) is typically donated for research purposes, including hESC generation (Fig. 1B).

The in vitro generation of hESC was first described in 1994 by Agriff Bongso (Bongso et al., 1994), and this breakthrough was a direct result of his laboratory's efforts to optimize the cell culture methods used in IVF. The procedure is depicted in Figure 1C, and it starts with thawing and propagating a superfluous donated day five pre-implantation blastocyst. The ICM is isolated and placed in growth medium. These cells can be cultured in vitro, but they require a supportive "feeder" cell layer to provide nutrients and hormonal signals. Typically, mouse or human fibroblasts (connective tissue cells) are used as feeders. If the procedure is successful, the cellular outgrowth of this ICM will form the "passage 1" of a new hESC line, and once the cell culture dish is densely grown with hESC, the cells will be harvested and transferred to five fresh cell culture dishes. There they grow again to cover the whole dish (passage 2), and be transferred to new dishes, and this procedure can be repeated continuously to generate more cells (Fig. 2). It is now possible, in principle, to expand hESC indefinitely, and hESC have been cultured as stable cell lines up to passage numbers far beyond 150 using methods developed orig- 


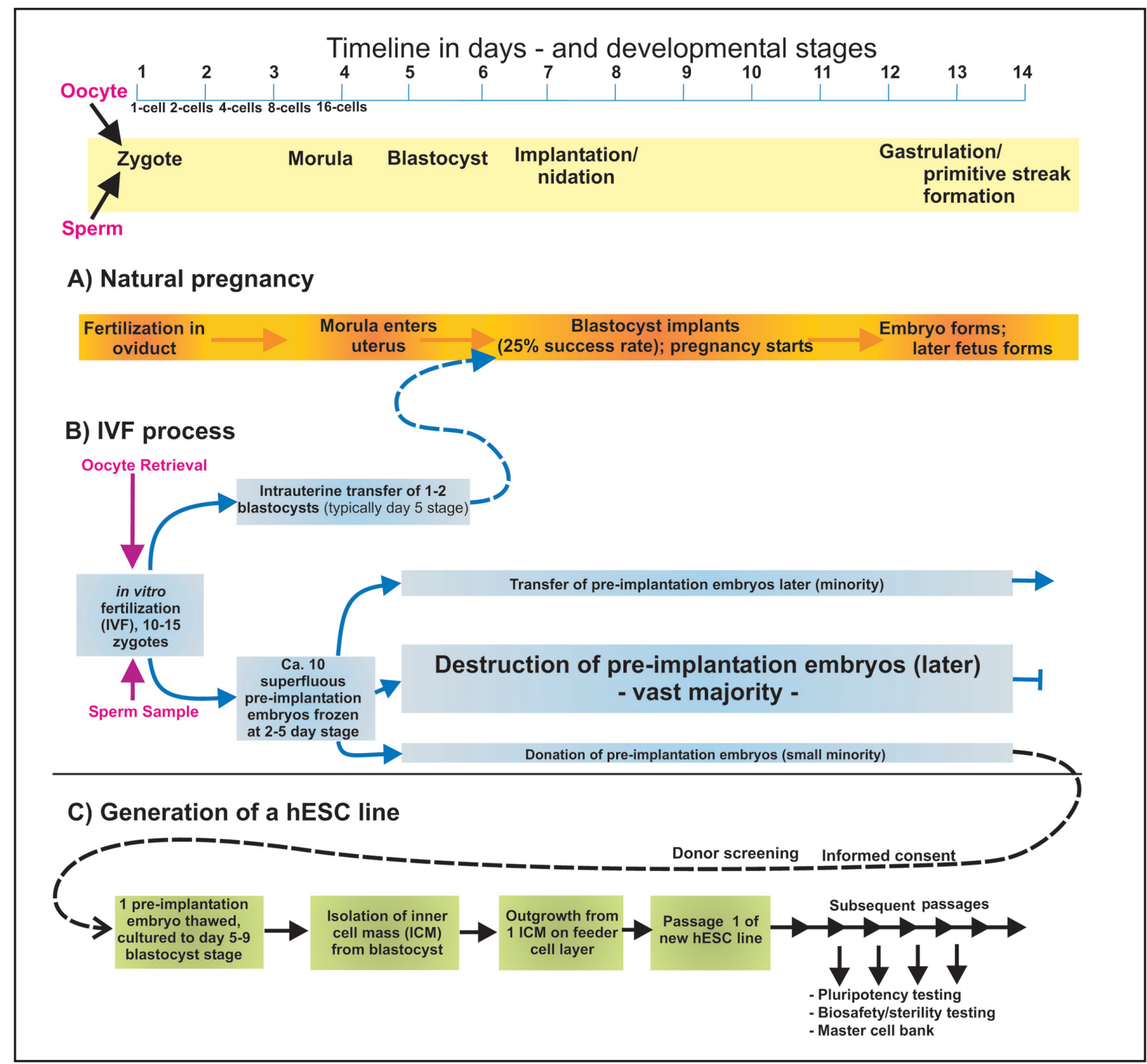

Fig. 1: Pregnancy, in vitro fertilization and the generation of hESC lines

The nomenclature for the developmental stages of the fertilized oocyte is shown for the first 14 days. (A) The different stages are shown in the context of natural pregnancy. (B) The different stages are shown in the context of in vitro fertilization (IVF).

(C) The procedure for the generation of hESC is shown in the context of IVF. The time line is different from that in B and C.

inally in 1998 in the laboratory of James Thomson (Thomson et al., 1998). hESC harbour the potential to form a diversity of different cells - theoretically any cell type of the about 200 existing in the human body. Therefore, they are called "pluripotent" cells. Pluripotent means that the cells can form any known cell type, but they cannot generate a whole organism, because they are lacking the capacity for implantation and formation of a placenta. This capacity is only found in the zygote and the cells up to the 8-cell stage of the morula, and these cells are called "totipotent". It is important to emphasize here that hESC themselves are not totipotent and they are therefore unable to generate a new embryo.
What do hESC look like?... and how does typical work with hESC look like? ....are questions that interest many people involved in the debate. Often, there is also the question of how often embryos are required..., how many cells can be gained from an embryo... and how all the other cells are derived from hESC. Research is often performed by specialists 


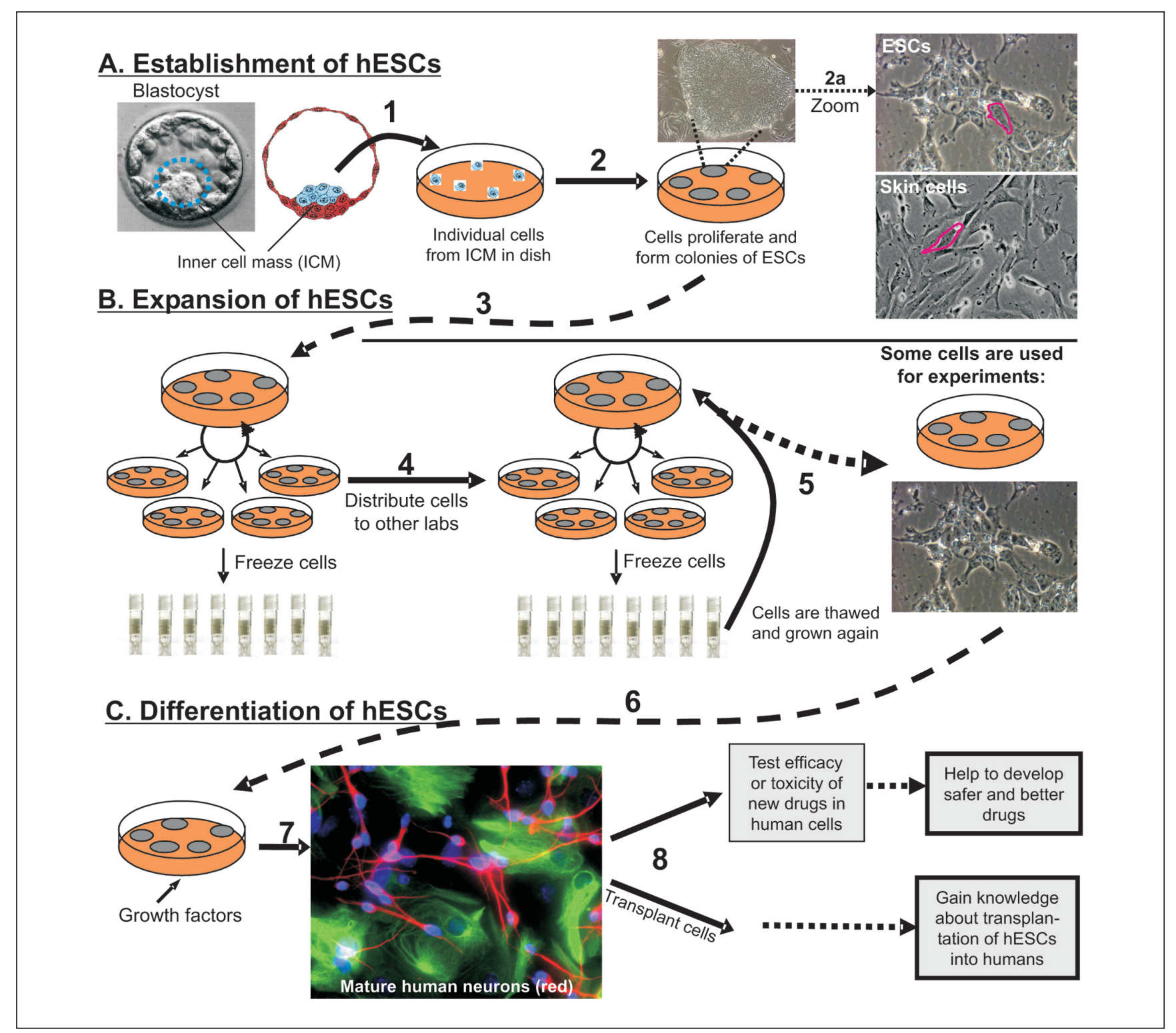

Fig. 2: The lifecycle of hESCs

1) A research group isolates cells from the inner cell mass (ICM) of a human blastocyst.

2) The cells proliferate in a culture dish and form colonies with cells lying closely together in a monolayer. 2a) When looking at the hESC at higher magnification, they resemble any other common cell type from the body (here compared to skin fibroblasts). The circumference of two individual cells is outlined with red in the cultures of hESC or fibroblasts, respectively, for better orientation

3) The hESC proliferate and are expanded to yield millions of cells, which can then be frozen in small vials to be used for future experiments. 4) Once the hESC are established, they are normally distributed to other research groups, where cells are further expanded and frozen. This expansion and freezing process can be repeated several times, ensuring that cells from one embryo can be used for many years in many laboratories.

5) The cells that are not kept for storage or for further growth, are used for experiments

6) To start an experiment, some of the hESC growing in the laboratory are placed in a new environment with growth factors that direct the differentiation of the cells. By choosing specific media, adhesion material and growth factors, the fate of the hESC can be controlled, i.e. the cells can be guided to develop into brain cells, muscle cells, or liver cells etc. The process of this "differentiation" can be studied in detail.

7) Alternatively, the cells are kept in the dish with growth factors until they have matured into the specific cell type desired (i.e. dopaminergic neurons for Parkinson's research or insulin-secreting cells for diabetes research). This can take up to 1-3 months.

8) The mature cells are now ready to be used for experiments (shown here is a culture of brain cells with the nerve cells in red and the supporting brain cells (= glia) in green). These cells may be used for transplantation studies in animals (e.g. an animal model of Parkinson's disease) or to test the efficacy or toxicity of new drugs on human cell types not available otherwise. 
trained for many years and using a very particular vocabulary which can make explanations difficult. Also, the public often has no idea what is actually done behind the closed doors of cell biology laboratories. This is a problem in discussions on the implications of this research that could easily be avoided. Therefore, information is included here that allows any reader, even one without biological training, to quickly get a picture of typical work with hESC (Fig. 2).

\section{Primary arguments: the status of IVF blastocysts}

While ethics is classically a philosophical discipline it affects many other fields. In particular, bioethics and applied ethics deal with topics that are of strong public interest. We believe that the discussion should not only be left to the experts in religious and philosophical faculties but involve broad circles, including biologists (McLaren, 2007). Opponents of this attitude sometimes claim that moral judgement does not require a complex ethical discussion, but a return to simple natural guidance principles. It is further claimed that ... instead of ethical discussions, it is mainly the capacity to say no, in cases where those natural guidance principles are in danger of being violated... Whatever approach one considers right, it will always be so that we can only judge on things as we see and comprehend them. A correct judgment therefore requires that we have a view of the facts that is as clear and as complete as possible, that information is true and valid, and that we understand the connections between the main components of the picture and the consequences of changes. For this reason, a picture of the ethical and biological background of the stem cell debate is compiled here in one review, bringing together biological background knowledge and other important non-biological issues.

\subsection{Issue 1: The question of killing}

The use of hESC in research requires the generation of hESC lines. The lines currently used were mostly produced from fertilized oocytes that had undergone about 7-8 divisions. The major objection to the use of ESC is that their generation is purported to involve an "act of killing". In extreme cases, even the word "murder" is used (Tab. 1) (Robertson, 2001).

According to common definitions, the act of murder requires a killer, a person to be killed, a killing act, a weapon and most importantly - low motives. In a classical detective story dealing with murder, the detective now needs to identify all of them, if they exist, and therefore we will scrutinize the current procedure of ESC generation for such details: First, the detective unravels the background story. A couple wishing to have children decides to try in vitro fertilization (IVF) - oocytes are removed from the woman, fertilized with sperm, and two embryos are implanted into the woman as detailed above. The remaining embryos are stored, frozen in liquid nitrogen, and the woman is lucky to become pregnant on the first attempt - possibly even giving birth to twins. Life goes on and the couple is content with their two kids. After more than five years of storage, the actual part of our detective story begins: Now, the quality of the stored blastocysts starts to deteriorate, and the storage is expensive as well. Presently, at least half a million such left-over zygotes are stored in the US alone. None of these blastocysts has any potential at all to ever develop to a human being without a foster mother. After parental consent of our happy couple, the leftover material will either be destroyed (moved to a trash can), or it may be donated for research purposes (only in some countries). Embryo adoption schemes as an alternative to discarding them were discussed and promoted by the pope, but this obviously does not appear to be a realistic option for all stored blastocysts at annual storage costs of several hundred million \$. In the case of research donation for hESC research, the blastocyst will be thawed, and hESC will be generated as explained above. When the procedure is successful, this will result in the generation of a single continuously growing hESC line that can provide pluripotent cells indefinitely. For instance the first such cell line, generated around 1998 (Thomson et al., 1998) has now been spread to scores of laboratories worldwide; its usage has generated a tremendous amount of novel scientific knowledge which may enable future therapies, and it is still being used extensively today. Most laboratories working with hESC nowadays use such cell lines for their research, but were never involved in the generation of cell lines, i.e. the use of any blastocyst as explained in step 1 of Figure 2. So far, this is the sequence of events, but can we really identify a killer, a killing $a c t$, a weapon, and most importantly which person was killed, and whether indeed low motives were involved...? It appears that a more differentiated approach is required than the one seeing hESC only as evidence of a crime story. First, more biological information will be helpful. A closer look into the way information on the subject matter has been disseminated, may help to clarify the reasons for many misunderstandings underlying the current hESC debate.

\subsection{Issue 2: The definition of embryos and pregnancy}

While some influential groups connote research on hESC as "embryo-consuming research", others wonder about the origin of this statement, in view of the fact, that the large majority of researchers working with hESC have never in their life seen a human embryo, as they are merely using hESC for scientific research but have never generated a hESC line. This applies to researchers of many countries in the world (MBBNET, 2008).

However, staying within the image of a crime investigation, one has to admit that knowingly profiting from someone else's crime or basing one's work on it would also be illicit and unethical. We have seen above (issue 1) that it is not clear, whether a crime is being committed at all in many hESC research applications. However, we still need to have a closer look at those labs where ESC lines are generated - and define exactly what they are generated from. We will deal later with the question whether the cell material used for hESC generation ever had the potential to become a human being. For now, we want to clarify the question of whether hESC are at all generated from embryos in a colloquial sense? 
Tab. 1: Overview over ethical issues

The numbering refers to the numbering of the chapters in this review. The major arguments for and against the use of hESC are shown in green. Issues that describe the debate on hESC itself and give background information are highlighted in yellow. Alternatives are shown in beige.

\begin{tabular}{|c|c|c|}
\hline \multirow[t]{2}{*}{ Issues: } & \multicolumn{2}{|c|}{ Arguments referring to the use of embryonic stem cells in research } \\
\hline & Supportive: & Rejecting: \\
\hline $\begin{array}{l}\text { 1. Killing } \\
\text { 2. Embryo consumption } \\
\text { 3. Human personhood } \\
\text { 4. Basis for personhood } \\
\text { 5. Simple rules } \\
\text { 6. Alternative start } \\
\text { 7. Significance of nidation } \\
\text { 8. Balance of values } \\
\text { 9. Protection of life } \\
\text { 10. Protection of the weak } \\
\text { 11. Human dignity } \\
\text { 12. Therapy as balance } \\
\text { 13. Prevention of damage } \\
\text { 14. Toxicity testing } \\
\text { 15. Basic science }\end{array}$ & $\begin{array}{l}\text { No killing; continuity of cell line } \\
\text { Use of waste material, not embryos } \\
\text { Gradual acquisition over } 1-2 \text { weeks } \\
\text { Nidation and maternal signals required } \\
\text { Not applicable to biological complexity } \\
\text { Brain (nerves) defines full personhood } \\
\text { Go - no go decision } \\
\text { Yes - differentiated views } \\
\text { hESC research perpetuates life of surplus IVF embryos } \\
\text { Nothing to protect in a nitrogen tank } \\
\text { Only partially assigned to blastocysts } \\
\text { Fundamental duty to heal, if possible } \\
\text { High benefit to mankind } \\
\text { High benefit to mankind and animals } \\
\text { Freedom of science: fundamental right }\end{array}$ & $\begin{array}{l}\text { Destruction of embryos } \\
\text { Use of human embryos } \\
\text { Full status at zygote formation } \\
\text { Continuity, Potentiality, Identity } \\
\text { New chromosome set defines life } \\
\text { Brain is only qualitative step } \\
\text { One of many steps only } \\
\text { No compromise or balancing } \\
\text { hESC is based on embryo use } \\
\text { Obligation to protect unborn life } \\
\text { Unconditional and absolute } \\
\text { hESC not acceptable } \\
\text { hESC not acceptable } \\
\text { hESC not acceptable } \\
\text { hESC not acceptable }\end{array}$ \\
\hline 16. Cultural aspects & hESC acceptable to many religions & Pope: absolutely non-acceptable \\
\hline 17. Slippery slope & Don't stop all progress on principle & Beware of first step \\
\hline 18. Rhetorics, use of & "pro-embryos" hESC "generation" & "Embryo-consuming"; "murder" \\
\hline 19a. Manipulation & Hopes for immediate therapy & Truisms and pseudologics \\
\hline 19b. Logical argument & \multicolumn{2}{|c|}{ Problem: Emotional arguments, often given logical or scientific appearance } \\
\hline 20. Ethical standpoint & Interplay of science and ethics & Absolute standpoint \\
\hline 21. Claim of authority & Scientific insight into complex issues & Defense of moral and values \\
\hline 22. Irrational fears & \multicolumn{2}{|c|}{ Confidence requires time and transparency; control helps to build trust } \\
\hline 23. Opinion formation & Learning process. Ethical re-evaluation & Ethics unchangeable \\
\hline 24. Practical responsibility & Care about consequences of hESC ban & Indifferent to consequences \\
\hline 25. Inconsistencies & Resolve by allowing hESC research & Resolve by banning abortion \\
\hline 26. Intellectual property & Patents do not restrict hESC research & No patents on life \\
\hline 27. Commercial aspects & Patenting of methods drives therapy & No commercialization of humans \\
\hline 28. Secondary interests & \multicolumn{2}{|c|}{ Must be separated from the real ethical debate and often confuse the public } \\
\hline 29. New cell lines & Required for high quality applications & Old cells must suffice \\
\hline 30. Adult stem cells & Have serious practical limitations & To be considered as alternative \\
\hline 31. hESC plus embryo & \multicolumn{2}{|c|}{ Preimplantation diagnostic: hESC generation without preventing pregnancy } \\
\hline 32. Promises of iPS cells & \multicolumn{2}{|c|}{ Do we understand them enough? How do we deal with new ethical issues? } \\
\hline 33. Nuclear transfer & Immuno-matched ESC; basic science & No oocyte use; instabilities \\
\hline 34. Disabled embryos & \multicolumn{2}{|c|}{ Discarded embryos as realistic source? Oocyte modification as dead end } \\
\hline 35. Issues of the future & \multicolumn{2}{|c|}{$\begin{array}{l}\text { Generation of gametes from hESC/iPS and in vitro interbreeding; parenthood and embryo definitions } \\
\text { of "somatically-derived zygotes"; nuclear transfer }\end{array}$} \\
\hline
\end{tabular}

From the abortion debate, there exists quite a clear concept of what an "embryo" looks like: Beating heart, facial structures, clearly-discernible arms and legs - and a size-dimension visible to the human eye or by ultrasound imaging devices. Such an "embryo" is called a "fetus" in medical terms. The fetal stage of development extends from the $9^{\text {th }}$ week after fertilization until birth. The inner organs, such as the heart, are developed and the brain is forming. In medical terms, only the very early stages of development, before the fetal stage, are called embryonic stages.

Why are such definitions important? Doctors, lawyers and policy makers need to know what they are talking about, and hence in these two disciplines clear definitions have been agreed upon to desig- nate exactly when a pregnancy starts: at implantation of the blastocyst - not before. This is precisely why measures that prevent nidation and therefore the establishment of pregnancy after fertilization are medically as well as legally, considered "contraceptives". Examples would be the intrauterine device (IU) which is a widely used contraceptive (currently 160 million woman according to the WHO), 
or emergency contraceptive pills given up to $72 \mathrm{~h}$ after a suspected conception, such as the progestin levonorgestrel (Wellbery, 2000). In contrast, pregnancy interruption (abortion) can by definition only happen after pregnancy has been established, not before. Accordingly, the embryo definition of the American encyclopedia of medicine starts with implantation (excluding the stages prior to it). As shown in Figure 1, implantation of the blastocyst occurs at around day 7 after formation of the zygote and hESC lines are generated from a developmental stage that occurs before implantation, i.e. in strict medical terms from pre-embryonic stages. Sometimes the terms "pro-embryo" or more exactly "pre-implantation embryo" is used for exact distinction of this stage. However, the term "embryo" may also be used generically to comprise all stages of development starting from the oocyte. It is just important to be aware of what is really meant. Knowledge of these precise facts should be prerequisite for opinion formation on whether embryos are indeed consumed for hESC generation. Whatever the result of this consideration, one has to be aware of the fact that the microscopic pre-implantation mass of less than 200 cells serving for hESC generation is not what the general public imagines in the word "embryo" (Fig. 2). Further intricacies of the embryo definition are discussed under issue 35.

\subsection{Issue 3: Beginning of human personhood}

It may be argued that size, morphology or exact medical terminology of an early human being do not really matter, if indeed a person is killed. Agreeing with this presumption, the definition of "human personhood" is the most crucial issue, and a wide range of viewpoints exists (Fig. 3):

- On one side of the spectrum one can find views that human life and personhood begin and reach their full extent within a single moment, when the nuclei and chromosomes of the gametes combine (day 1 in Fig. 1).

- On the other side of the spectrum one finds views that the first days after the zygote formation merely result in the formation of a "pile of cells" (morula/ blastocyst stage, up to day 10 in Fig. 1) which cannot yet be assigned full hu- man rights and therefore does not deserve the specific ethical consideration of a person (Schuklenk, 2008).

- In between these extremes, there are also views that acknowledge the zygote as being unique (as opposed to other cells) in its natural, but theoretical, potentiality to become a human being, but that full human personhood and the rights associated with it are acquired gradually. Here, metaphors are often evoked of the embryo being a walnut, a cherry or a caterpillar, which may or may not become a walnut tree, a cherry tree or a butterfly - but they certainly are none of the latter, and therefore they deserve a different status. No one would, for instance, argue that each walnut deserves the same protection as a full-grown walnut tree.

These views greatly differ according to country and culture. For instance, the Catholic Church, and countries with a strong Catholic influence on politics tend towards the first version, whereas most Jewish and Muslim communities favor the second version. Countries with strong protestant churches have largely varying attitudes. For instance, the last version is officially supported in the UK or Sweden. There, the embryo has some initial moral status because of its human origin and its theoretical potential of becoming a person. Therefore clear limitations and stringent controls exist for embryo-related research, such as the justification of research by other values and realistic goals, required approval from an established ethics board, and the use of embryos only from certain sources. The status increases over the first 2 weeks of development to reach full assignment of personhood after 14 days and thus the full status of human dignity and its protection. Similarly, more liberal regulatory frameworks were adopted by other countries, namely Singapore, Australia, and Israel, whereas the USA adopted a more restrictive approach (MBBNET, 2008).

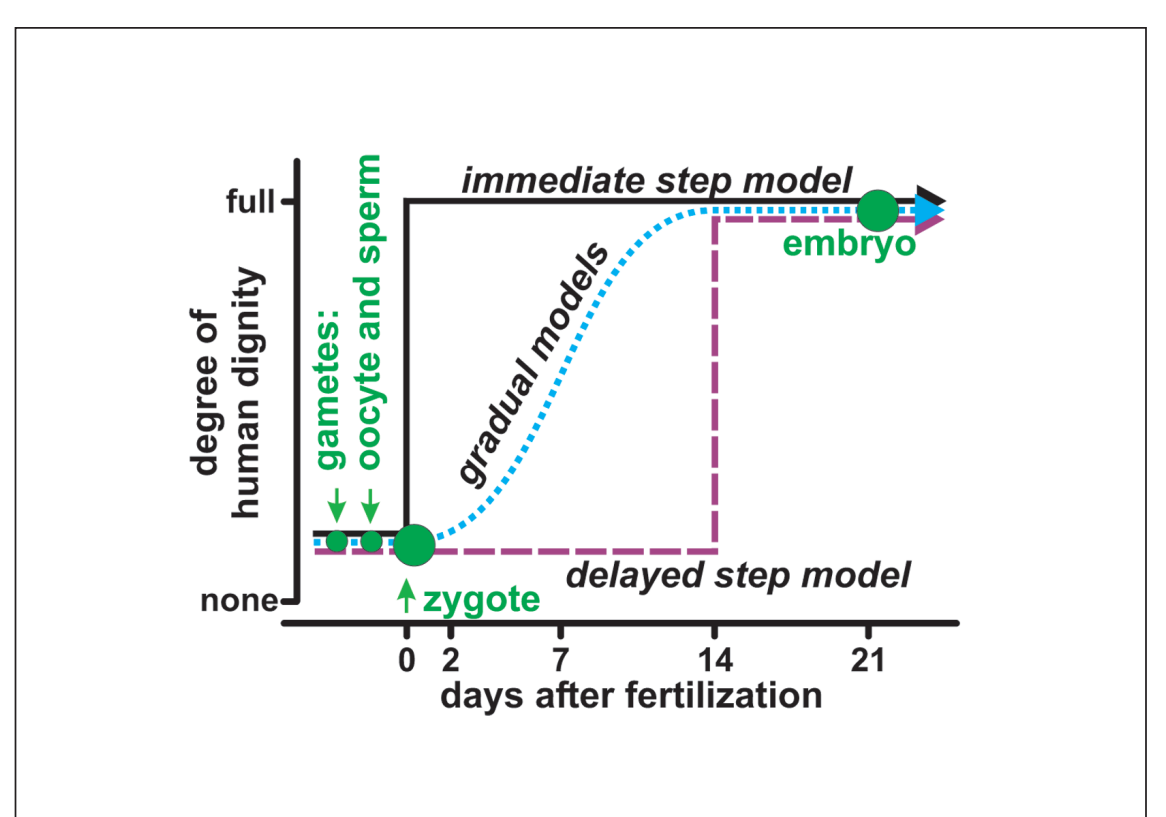

Fig. 3: Different models to explain the beginning of personhood and the assignment of human dignity

Initially the gametes fuse to a zygote. This time point is arbitrarily set to zero on the time scale. Note that the state of the human dignity is larger than zero also for the gametes. They are donated human tissue with a particular status. The black line describes the view of the world of different churches (e.g. the Catholic Church). The blue line stands for different views, that assume that the zygote does not have the full personhood status, and that this status is reached over time in parallel with certain biological steps (nidation, development of tissues, development of the nervous system ...). The red line stands for models based on one defined event, day (e.g. by legal definition) or biological process in the development of the embryo, which leads to full assignment of human personhood. 


\subsection{Issue 4: Personhood of the embryo}

We have no authority of deciding who is right in the above issue (issue 3), but we can look at the basic concepts associated with these different views.

One line of thought builds on the concepts of continuity, identity and potentiality. Obviously, a zygote does not fit our intuitive and accustomed picture of a human being. Still, it clearly belongs to the human race (biologically). In order to assign the status of personhood to a microscopic pile of cells, is has to pass at least the test of the following characteristics:

- A defined succession of events leading invariably from the zygote to a human person (= continuity);

- A situation in which one zygote only becomes one person and one person can only be derived from one single zygote (= identity);

- The full capacity of a zygote to become a human person without further manipulation or help (= potentiality).

If one accepts that these three requirements are met, and if one assumes that fulfillment of these requirements is both necessary and sufficient for the personhood definition, then a zygote indeed is a human being.

However, biological research in mammals has shown that these assumptions may not hold true: The continuity criterion is not fulfilled, because most zygotes $(\sim 70 \%)$ never become persons (because of implantation failure), the identity criterion is not met, because one zygote can produce twins, and vice versa some persons are made up from two fused zygotes, and the full potentiality is not found in the zygote, as an embryo can never develop to a person in the absence of the mother's womb, i.e. without maternal signals received upon implantation. It may also be argued that these requirements are necessary, but not sufficient (see issue 3, gradual acquisition of personhood).

These are indeed serious biological objections to the personhood status of the zygote. In defense of this status, it is sometimes argued that we can indeed not be sure whether a zygote (or a blastocyst) fulfills the criteria for personhood, but if there was only a slight chance that it may be so, we need to assign it this sta- tus. Following this argument we would indeed be ethically on safe grounds to assign some human status to a zygote, but the question on whether personhood and human dignity are acquired in one step or gradually would then still remain unresolved.

A different line of argument addresses the time point of the acquisition of personhood more directly. It takes its origin from the utilitarian school of bioethics and asks whether the embryo has an interest in itself or its fate. Personhood is strictly associated with a concept of individual interest, at least in its most primitive and basic sense (e.g. pain, hunger with reference to a self). It is then concluded that, as the blastocyst has no nerve cells at all, it cannot have even the most primitive form of an interest and therefore it cannot be assigned full personhood (Singer, 1979).

\subsection{Issue 5: Simple is beautiful - or not?}

The arguments above appear intricate as the Gordian knot. One feels tempted to solve the problem with a single cut, like Alexander the Great. This solution is for instance offered by the Catholic Church, which declares that the soul enters the zygote at the exact moment of nuclear fusion during fertilization (day 1 in Fig. 1). As ensoulment is associated with full personhood, this provides evidently a clear definition of status and time point. To some extent the theological definition of personhood is also supported by biological concepts. This new combination is at the basis of a new creation, of something never having existed before and having a unique identity (unless we look at the two exceptions - when twins are formed from one zygote, or when fusion of two zygotes leads to one embryo). The genetic composition makes the major difference in the construction plan of parents and children.

However, living beings are not only construction plans, but actually real constructions. On this level, the situation is less clear. For instance, we know nowadays that the zygote is naturally very rich in maternal genetic and non-genetic information, which is initially absolutely dominant and is diluted out only over time (i.e. over several cell divisions) to give way to the information now encoded by the new mixed genome. Thus, the time point of nuclear fusion is not so unambiguously clear, as it may appear at first glance. It is one of many potential time points to define the beginning of personhood, initially chosen for clarity and simplicity. In addition, we have learned that our personality is not only a product of our genes. Now, in the age of epigenetics - which means influence of the environment on gene expression - additional factors are being discovered every day. When the time point of ensoulment was chosen, there were no major practical implications, whether it was this time point or some days later. Now, the choice of this time point is at the basis of an ethical dilemma for many people. This does not only involve hESC research. For instance, the definition of life by the Catholic Church means that a lot of life is created that can never receive the holy sacraments of this church (as a large proportion of pre-implantation embryos dies unnoticed before nidation), and it also means that IVF embryos not used further would require a formal funeral. Therefore, it appears fair to ask the question, whether such an important time point should be chosen and maintained just because of its apparent simplicity at times when it was defined, or whether it should not undergo (biological) re-evaluation - as it occurred many times before in history.

On the side of supporters of hESC research, there are also attempts to reduce the ethical problem to a single issue that can then be addressed easily. At the basis of their consideration is the claim that ' a woman from whose oocyte an embryo is formed in vitro is (together with the co-progenitor) the only person in the world privileged to decide whether the embryo will be transferred to the uterus' (Guenin, 2005). It is purported that no moral obligation can exist for the woman to undergo the transfer of the embryo or to allow adoption of the embryo by a foster mother. Thus, if the woman actively decides against intrauterine transfer, and gives informed consent for donation of the embryo for research, then it must be regarded as belonging to a "special set of embryos". This set is defined 
as, being barred from the womb. By all logics, such embryos have no potential to develop into a human being. No possible person would correspond to such an embryo. Thus, it could be considered and used under the regulatory guidelines of the transplantation law. This approach would solve many ethical issues, but there does not seem to exist basic agreement on the initial assumptions. In many countries it is not accepted that responsibility for the fate of the embryo lies only with the oocyte donor, and even the right of a woman to refuse implantation is contested in some countries such as Italy. It is also unclear how, in this situation, production of embryos for research would be distinguished from left-over embryo use. Thus, the approach can be helpful, but it is possibly oversimplified. It is in most cultures not the ultimate and simple solution to the problems of hESC use.

\subsection{Issue 6: Symmetry of life and death}

How do we arrive at a rational, clear and generally acceptable definition of the beginning of personhood, which can substitute one based mostly on the wish to keep it simple? A related problem arose when the time point of death needed to be defined. For instance, after a motor cycle accident and severe head trauma, the brain can stop working while the heart (if supported) may go on beating and supplying the organisms with oxygen and nutrients for days and weeks. Organs thus remain viable and usable e.g. for transplantation. Once the heart stops beating, individual cells can still remain viable for many hours or days, and be isolated for tissue cultures. The DNA, earlier supposed to be the determinant of personality, can remain stable for many years (e.g. when the body is rapidly frozen). Thus, death occurs at many levels, and - most importantly - in a gradual fashion. A simple, easily intuitive and historically validated definition may be the stop of heart beat for a certain time. However, what happens, when a heart is transplanted or a cooled body is reanimated? Ethical dilemmas arose due to a technological innovation.

To define death, one could alternatively ask, when does personhood end? What makes up a person as opposed to a human body? It is the capacity to think, to feel, to have awareness, including self-awareness and the capacity to have ideas, interests and emotions. None of these would be possible without a brain. Therefore the legal definition of death is based on the absence of brain activity, even though all the rest of the body is viable. Indeed, a living body without a brain would be a mass of cells without personhood. Notably, it would still be endowed with a certain degree of dignity.

The example of the definition of death has implications for the personhood definition on the other end of human life:

- First, we can learn here that a mass of cells is not necessarily only a mass of cells. The above case gives a good example that this would be an oversimplification that nobody intends. In all cultures, the human body (mass of cells) is not just a "thing", and it requires due respect, even though it does not have the same rights and status as a human person. Similarly, research with any human tissue, be it a medical specimen, a transplanted organ or a cultured cancer cell line, is under some degree of regulation and ethical oversight. Why should this approach not be applicable to very early human developmental stages as well?

- Second, the absence of neural activity means that typical characteristics of personhood cannot be present. In extreme cases of brain death (Erlangen baby) the body can still function for weeks and even support pregnancy, although it does not have a personhood anymore. In this case we have accepted that the human body without a functioning brain is not regarded as a live person. We do not know when the embryonic nervous system starts functioning, but we know that it cannot function before it is developed, and we know when it starts developing. Before that time point, we would deal with human tissue, requiring respect, but not possessing the status of full personhood. If we look at time points where tissue development has not even started (before implantation and gastrulation of the blastocyst at day 7-10, see Fig. 1) - would it not be reasonable to see this as being a symmetrical case to brain death? Or in other words, if we agree that a person who has lived and left traces in the world by the interaction with other people, by friendships and by family relation, is no longer alive when brain activity is gone, then how can we claim that an embryo which has never had any form of neuronal activity or personal interaction is a living person?

\subsection{Issue 7: Nidation as qualitative or quantitative step}

For some, it would be hard to accept that the definition of personhood could be linked to the development of the nervous system. Such a definition may look biologically fuzzy. Therefore, another attempt to define a rational and clear time point for the start of personhood focuses on nidation (=implantation). As discussed above (issue 2) and illustrated in Figure 1, this biological step forms the basis for the medical and legal definition of the start of pregnancy. As pregnancy can only be interrupted after it has started, abortion can legally and medically only apply to procedures initiated after nidation. This situation suggests a different status of the embryo before and after nidation. Such a view would at least be legally consistent. But again, there are different viewpoints. These depend largely on whether nidation is seen as a qualitative or quantitative step, i.e. whether one assumes that a new quality of human development is reached after nidation or whether one just sees this as one of many steps in the continuous development of the zygote to a fetus.

- Supporters of the qualitative nature of nidation claim that continuity and full potentiality are only reached after implantation of the blastocyst, as many blastocysts are lost before implantation, and there is a strong maternal influence that constitutes an essential developmental step. A variant of this view is that nidation is one of a series of qualitative steps. It may either be seen as the last decisive step after which full personhood can be assigned - or as essential prerequisite for gastrulation and primitive streak formation after which full personhood can be assigned.

- Supporters of the quantitative step claim that zygote formation already results in 
full potential, as the effect of the implantation is minor or may be bypassed when more technical and biological knowledge becomes available. Also, that maternal signals and a differentiation axis are already present before nidation, but are possibly not detectable by present technology. Moreover, some claim that the loss of most of developing zygotes (up to $70 \%$ ) before nidation would not mean that the basic principle of continuity is not fulfilled, as death can, for instance, happen also to babies after birth without their personhood being questioned. For an elaboration of the latter point see also issue 19 (different logics).

\subsection{Issue 8: Choices of reality}

It appears hard to find scientific arguments for one or the other position that could not be disputed to some degree. Many other dimensions of argumentation have therefore been explored: legal, religious, medical, philosophical, and others. Although this theoretical exercise is a highly important process for society, one should not neglect to make a reality check from time to time to see whether theory is still coupled to reality. Let's look at some imaginary stories: For instance, let's assume that ESC-based therapy has been developed in your neighbor country (e.g. France or the UK) and is used successfully and safely e.g. for Parkinson's disease. The therapy itself may not imply the use of ESC at all. Your spouse or a parent get the disease. Would you seek this therapy, if it was available in your own country? Would you seek this therapy in your neighbor country? If that therapy was forbidden in your own country, should your spouse/family seeking it abroad be held morally guilty of killing embryos? Or would you prefer to let others deal with problems of hESC research and then benefit in the end? Another reality check often mentioned in the stem cell debate is more extreme, but still useful as food for thought: A young couple has undergone an IVF procedure. Three good oocytes were successfully fertilized. One was implanted and resulted in a baby (e.g. one of the $1-2 \%$ children born e.g. in Germany from IVF). Two were frozen. They are stored in a cryocontainer in liquid nitrogen together with
100 other frozen zygotes (embryos). One year later, the wife has an early morning appointment at the IVF clinics for a hormonal check for future planning. The doctor is in a wheelchair. Neither one of them initially notices the fire starting that prevents them from taking the elevator. The wife now has the choice of either saving the doctor by assisting him down the stairs and out of the house, or moving the 100 embryos (including her own two) in the big cryo-container. What would be her most likely choice in a real world?

\section{Secondary arguments: balance of values}

If one agrees, that the zygote has some type of special moral status, be it partial or complete personhood, then it cannot be used without certain restrictions. This situation is not specific for hESC research, but applies generally to the use of human material and in particular for transplantation. The field of organ donation and use of tissue for medical purposes has had a long time to deal with ethical issues and mature viewpoints have been developed and transformed into guidelines and legislation. One of the underlying principles is that the use of human material is acceptable, but needs to be justified by a real or envisaged benefit of another human being or by the progress of science which serves a greater good. In some countries the practicability-tested ethical framework developed for transplantations has been adopted for the use of pre-implantation embryos. This applies to the rules pertaining to the source of the material, to the informed consent and to the guidelines for the potential use of the pre-implantation embryos. Whatever country or culture, a reasonable balance of values must be evident in order to use human material, including hESC.

\subsection{Issue 9: Protection of life}

Arguments supporting a use of hESC in cases when the value balance appears correct (see issues 12-15), are frequently wiped aside by the claim that protection of life supersedes all other values. This line of thought further implies that giving up of hESC research and banning of
hESC generation would result in a protection of life. A particularly important aspect of the discussion on protection of life is the claim that this must be unconditional, and that lives cannot be balanced against one another. These are arguments that need to be taken seriously, but these arguments also require great care and responsibility when they are used.

The imperative of the protection of human life is universally accepted, but also repeated without reflection like a mantra. Therefore, one wonders what is really meant - or indirectly implied - when this is mentioned. Often the argument is not as innocent and pure as it appears, but it is used as an accusation that someone is not willing to protect human life. In the context of hESC, the use of this argument implies that hESC research destroys life instead of studying life, maintaining life and preventing harm to life. In countries (such as Italy, Germany) where no hESC cell lines are generated, researchers can get permission to work with certain preexisting cell lines. The research they carry out (covering the entire activity of several large countries) does not sacrifice a single life, directly or indirectly. Whether this research is performed or not - it has no effect on the previous generation of these cell lines. The cell lines have existed for several years, and their present use does not lead to the use of a single additional embryo. Unaware of this, a lot of people have been misled by the apparent argument of "protection of life".

The situation presents itself different in countries where hESC may be generated. Under certain assumptions, one may build a case for the protection of the life of the blastocysts used for the generation of the cell lines (see discussion above on issues concerning the beginning of life and personhood). This argument would be valid and consistent under the assumption that full human personhood begins at fertilization of the oocyte. However, it remains a theoretical argument that does not live up to the practical reality. The decision on the fate of a fertilized egg is not taken by the researcher trying to derive hESC cells. The decision has been taken long before by the parents and IVF doctors involved. They have decided against an implantation of the embryo into the woman. Without implantation, the "embryo" has no continuity 
and potentiality and thus also in all possible views and interpretations no chance of ever becoming a human person.

At this stage the blastocyst is called a surplus IVF embryo, and only at this stage, when the decision on life (or not) has already been taken, can a scientist consider the material for use of cell line preparation. It is important to note that surplus frozen embryos from IVF represent in practice an almost unlimited source for the generation of hESCs. Therefore life is not generated through fertilization of oocytes with the sole purpose to "destroy" them to obtain a source of hESCs. With the use of these embryos, life is not extinguished, as would happen when the surplus IVF embryos are discarded, but the biological life is even maintained and perpetuated. In view of this situation, objections to hESC research due to the argument of the "protection of life" appear somewhat hypocritical.

\subsection{Issue 10: Protection of the weak}

An important argument sometimes used against hESC research is our obligation to protect the weak. Like the protection of life discussed above, this has a strong emotional aspect and easily generates consensus. Protection of the weak often means protection of a weak individual, even at the immediate disadvantage of others or the larger community. This concept of "reciprocal altruism" is a highly important part of human culture, even though it is not only out of ethical reasons, but also driven by the fundamental underlying psychology that we would like to make sure that others would help us, if we become weak. Thus, probably all sides agree on a duty to help the weak. However, the use of this argument in the hESC debate requires great care and responsibility, as it easily diverges attention from the real issues and because this argument has the potential to be misused. For instance, this argument has been used when a group of professional revolutionaries took over the Russian empire in 1917. It was used to prevent women from gaining full equal rights, colonies from gaining independence, and slaves from gaining their freedom. One common issue in all these cases is that the "protected" ones had not been asked or could not express their intentions whether they wanted this protection.

Similarly, we also do not know whether surplus IVF blastocysts desire this protection. We do not know whether they "prefer" to be disposed of or have their existence prolonged 180 degrees in a nitrogen tank, over the transformation into an hESC cell line. However, we know one thing for sure, that wanting, having interests and intentions, are hard to imagine without any form of nervous system, and blastocysts do not contain a single nerve cell. It is therefore entirely unclear what actually "protection of the weak" means in this context. Even if we would assign full personhood to blastocysts, what would be the best fate for them if we seriously want to "protect" them? Theatrically-speaking: "Eternal imprisonment in liquid nitrogen", "growth in a cell culture dish" or "rapid death in a trash can"? Hence, we need to find some clarity, before we can seriously consider the argument of "protection of the weak".

\subsection{Issue 11: Inviolability of human dignity}

Within the triad of fundamental moral arguments, protection of human dignity complements protection of life and protection of the weak. Again, the argument appeals at an emotional level, and it builds on a recognition effect. We all know the principle of the inviolability of human dignity as fundamental right from constitutions, declarations and human rights charters. The imperative is self-evident and learned from early childhood. It is the highest principle of most Western constitutions, but it is also astonishingly difficult for many to define exactly what is meant by human dignity. It signifies that all human beings possess inherent worth and deserve unconditional respect, regardless of factors such as age, sex, abilities, social status and intelligence. This respect is owed to every individual by the mere fact that he or she is a "member of the human family" (Universal Declaration of $\mathrm{Hu}$ man Rights, 1948, Preamble). In practical terms, human rights derive from this inherent human dignity. Another important aspect for the hESC cell debate is that dignity makes every person irreplaceable. It prevents instrumentalisation of a person or price setting, and thus it prevents value balances as discussed above. The life of one person cannot be balanced by any other value, including the lives of other persons. The fundamental nature of this position is important for the understanding of the debate on the use of human embryos. Viewpoints on the fundamental question of human dignity cannot be relative (balanced) in many legislations. An example from the German legislation exemplifies how high this principle is held: $\S 14$ of the "Luftsicherheitsgesetz" (a law concerned with air traffic) would have allowed that a plane, hijacked by terrorists and directed towards a huge sports arena to kill tens of thousands of people could have been shot down. This law was declared unconstitutional, because it would lead to voluntary killing of the hostages, even if these would only have survived 5 more minutes until the crash. In simple mathematical terms; human life is assigned an endless value, and then 100,000 times endless (the lives of spectators in the arena) is not more valuable than 5 or 50 times endless (the lives of the hostages). If we want to be true to our constitutions and their current interpretation, then we cannot justify embryo research by a balance of human lives against other benefits. However, we can ask when in life personhood begins, at what rate it grows and when it has reached the level when full human dignity applies. If one assumes partial personhood up to the blastocyst stage, the balance of values becomes important. If full human dignity applies from the moment of fertilization as proposed by the Catholic Church, then indeed a consequent standpoint is the rejection of hESC research. Alternative views to the extremely unconditional view of human dignity are discussed under issue 24.

\subsection{Issue 12: Therapeutic applicability}

The value most frequently discussed in the context of hESC is their therapeutic applicability. This argument has been promoted so violently, that it is often perceived as the only argument favoring the use of human blastocysts for research. The vision of healing diseases ranging from cancer and neurodegeneration to diabetes and stroke is appealing and the 
strong enthusiasm based on this vision may have contributed to some blurring of the borderline of science and science fiction. To some extent the argument of therapeutic use was utilized to exert moral pressure on those objecting to hESC research, and furthermore the sparkling vision of new hESC-based therapies was (and is) vividly promoted by small Biotech companies that were (and still are) in need of raising funding in a difficult environment with most big pharmaceutical companies avoiding this area altogether. On the other hand, the argument of the therapeutic applicability is often equally bluntly refuted by adversaries of hESC research in order to avoid such moral pressure. Their reasoning is that the potential therapeutic applicability in the future is of limited value now, and only of theoretical nature concerning the balance of values. The above views are extremes, and each indication needs to be evaluated individually for a reasonable judgment.

What are the facts about the therapeutic potential and why is this issue so important? Concerning the latter question, we need to recall that the stakes are high in this debate. It is about human living material in one or the other form, which is used for research, and which is derived from material, which at some time had a certain potential of becoming a human being. A value of equal moral weight would be the healing of sick human beings, i.e. the prevention of pain, suffering and death. The ethics of healing is as old as our culture, and many religions teach a duty to help and heal. This requirement to heal, whenever possible, is particularly strong in religions related to or based on the old testament of the bible. In the Jewish tradition, for instance, the primary importance for saving lives and helping suffering patients takes precedence over the fears generated by modern genetic and reproductive research. Provided that new technologies are applied for medical indications and respecting human rights and human dignity, it is legitimate to explore their beneficial potential (Revel, 2003). Therefore, the argument of therapeutic applicability has been so much in the focus of the hESC debate. In order to understand the term "therapeutic potential" it is useful to look at its three different dimensions separately:
- Transplantation: The primary application dominating public discussion is the generation of tissue from hESC cells for purposes of transplantation to replace deficient tissue in a patient ("cell therapy"). One may for instance generate precursors of dopaminergic neurons and use them to substitute the loss of such cells in Parkinson's disease, or one may generate insulin-producing cells and transplant them into diabetic patients. In other cases bone, or connective tissue, or skin may be produced to help patients after burn injury and trauma. It appears at the moment in the field of regenerative medicine that there are many diseases and conditions that cannot be healed by drugs, and where cell therapy may be an additional option. Further into the future, perhaps infarcted brain or heart tissue may be repaired. The present therapeutic promise of hESC research is comparable to the status of gene therapy 10-15 years ago. We have to admit that gene therapy has not yet fulfilled much of its promises. It is also clear already now, that not all diseases will be cured by transplantations. Even in diseases with a good rationale for transplant therapy, such as Parkinson's disease (Björklund et al., 2003; Li et al., 2008), the success and scope of classical transplantation has until now been relatively limited. It also has to be considered that the problem of tissue rejection has not been solved for hESC-based transplants. Very basic problems, such as the production of sufficiently high cell numbers and pure cell populations to test the therapeutic use, have not yet been overcome, not even for a single therapeutic indication. Notably, the first potential clinical trial initiated by Geron that intended to use hESC-derived material has been put on hold by the FDA just recently (Baker, 2008). Although there may be a great potential to heal certain diseases by tissue replacement therapy with hESC, this potential may be far less than sometimes stated in political debates, and it will probably take another 10-20 years before we will have a good guess which ones they will be. However, the use of stem cells for trophic effects and immunomodulatory therapy may yield therapies sooner.
- Indirect development of therapy: hESC have more therapeutic potential than just transplantation. Research on hESC is important to gain understanding about endogenous tissue-forming and regenerative potential. This will form a basis for future therapies stimulating endogenous repair mechanisms or preventing degeneration due to defective differentiation. A broad understanding of hESC differentiation pathways will also be an important step toward the generation of new tissues from other cell sources. These may not be available yet in significant quantities (e.g. brain precursor cells), but may be generated later with help of knowledge gained from hESC research (Guan et al., 1999). hESCbased systems may also significantly aid the production of vaccines and other biological therapeutics. Finally, the fields of stem cell research and gene therapy may synergize some day by using stem and precursor cells as vectors for a successful gene delivery. Knowledge gained from hESC cells will most likely be very valuable here.

- Help for development of classical therapy: Another therapeutic benefit of hESC, which may be realized relatively soon, is the application of hESC-based test systems for the faster and better development of classical drugs (SC4SM, 2008; Schrattenholz and Klemm, 2007; Klemm and Schrattenholz, 2004). Major pharmaceutical companies like Novartis, GSK and Pfizer have only recently started to involve themselves in hESC technology by forming a consortium that funds hESC research (SC4SM, 2008). Also biotech companies such as ESI, that had a strong focus on cell therapy, are now shifting attention towards test systems (Baker, 2007), and the leading European companies such as Stem Cell Sciences and Cellartis have for many years worked according to a business model directed towards test systems. Similar to animal models in the past, hESC-based systems may provide new insights into human disease pathways and facilitate discovery of new drug targets (Luttun and Verfaillie, 2006; Strübing et al., 1995; Wobus and Hescheler, 1992). Likewise, in drug discovery programs, efficacy and safety of drug candidates may be optimized on 
ES-based test systems (Buesen et al., 2004; Seiler et al. 2002, 2006; Whitlow et al., 2007; Leist, 2006). This potential use applies to many diseases where transplantation is not a therapeutic option, and thus may accelerate the availability of new and safer drugs soon. A special variant of this approach would be that disease models can be developed on the basis of human genetic defects (Pickering et al., 2005). So far, this approach has been relatively neglected in the ethical debate. For instance, the companies using hESC-based systems for drug discovery will not only do this for the benefit of mankind and for the commitment to healing, but also for the profit of their shareholders. It will be difficult to dissociate one from the other and to fit this into an equation balancing the different values at stake.

\subsection{Issue 13: Benefit to mankind} The healing argument falls within a larger category of "being of benefit to mankind". Healing is only one side of the coin that represents overall public health. The other side is prevention of damage and disease. If the latter is successful, healing becomes obsolete. If the latter is neglected, healing can only mitigate the consequences, but not prevent suffering to its full extent. An application of hESC, different from therapy, but still of high moral value, would be the prevention of damage. A typical example for this would be the use of hESC-based systems to detect environmental toxicants that would cause human developmental toxicity. In contrast to the therapeutic use, results of this research would be expected in the very near future. Concerning the balance of values, it may be argued that prevention of damage is of lower moral status, than healing, as the former only addresses the potentiality of damage, while the later addresses an existing problem. However, the opposite argument would also make sense: such that it is better to prevent damage than to heal what is left over after it occurred. This issue is a general and continuous dilemma of health politics world-wide and has yet to be resolved.

\subsection{Issue 14: Benefit to animals}

It has been argued that hESC can by no means be used to substitute animal experiments. This would mean that experiments are instead performed on "humans". However, this argument contains a misconception. The testing of toxicity on human cells allows man to take responsibility for himself without relying on animals and their suffering. It would not be a substitute, but an entirely different, and possibly better approach. Human cell-based in vitro methods would fully correspond to the new vision of a mechanistically based toxicology (Leist et al., 2008b; Hartung and Leist, 2008) that implies higher financial efficiency of the procedure and improved safety for mankind. For instance the EU project ESNATS has been started with the goal to develop novel hESC-based alternative test systems for drug profiling. The program involves small-to-medium sized biotechnology companies, around 2 dozen research laboratories throughout Europe and a steering committee giving professional input on industrial applicability, ethical questions and utilization of discoveries. The project also involves major national and European authorities involved with finding alternatives to animal experimentation. This is a logical consequence of a line of research that has shown that $3 \mathrm{R}$ (reduction, replacement, and refinement of animal experiments) methods have been astonishingly successful and can sometimes yield better data than animal-based tests (Hartung, 2001, 2007a, 2007b, 2008; Leist et al., 2008b). hESC-based test systems could contribute to such a strategy of safety testing with fewer animals, and with data more relevant to humans, and more based on sound science. This concept should by no means be mistaken (or distorted) to imply that animal experiments would be substituted by embryo research. Typical examples for the application of hESC at the moment are in the field of developmental neurotoxicity. The thalidomide catastrophe showed that animal models can be very poor predictors of human developmental toxicity. Accordingly, a lot of focus has been on the development of ESC-based test systems, initially on murine cells, and in recent years also using human cells (Pellizzer et al., 2005).
Research on human neurons is extremely difficult due to the poor availability of the material. Therefore, most experiments to test toxicity have relied on animals or animal material, and this has sometimes led to detrimental erroneous conclusions (see thalidomide). Another illustrative example is cardiotoxicity (in particular toxicity of drugs that cause changes of the heart beat). This is frequently associated with drugs that interact with the socalled hERG potassium channel on the heart. It is likely that in the near future, hESC-derived cells may be substituting the current assays performed with primary porcine or rabbit cardiomyocytes (heart muscle cells). Such cells can now be generated from hESC with almost $100 \%$ purity, and these cells have been shown to function in the hERG test $(\mathrm{Xu}$ et al., 2008).

\subsection{Issue 15: Scientific progress}

A value different from therapeutic use, is scientific progress. Scientific progress may eventually lead to improved therapies, but there is only a loose and rather indirect connection between the two. Still, everyone born in rich industrialized societies has benefited from the fruits of past research and it is scientific research that will discover ways of combating the dangers to come. Independent of the practical benefits of science, the freedom of scientific research per se is a basic civil and political right because it is a dimension of freedom of thought and freedom of speech. Thus, a high value is at stake here too, although the weight of the argument is less obvious to the public than the therapeutics rationale. Scientific progress remains a very theoretical argument for those not deeply involved in science. Therefore, the importance of the issue is underestimated. As scientific progress is no good political argument, it is not promoted as much as it would deserve. Three lines of argument illustrate the importance of basic research with hESC:

- The first refers to developmental biology. It is one of the wonders of nature, that on the one hand, a complete animal or human being can develop from a zygote, and that on the other hand stem cells can retain infinite replicative capacity in an undifferentiated state. We 
can study these two phenomena in flies and worms, but ultimately the most exciting results can be expected from studying man. Other "model organisms" are only poor substitutes, since development of human beings differs in various essential aspects from the development of other species. We will not understand our own development, if we ban this research. We will not understand what makes our own stem cells be a stem cell, and what determines their potency for differentiation, and neither will we understand why differentiation is mostly a one-way road, and how cancer cells find a way to reverse the direction on this road.... It is an inborn desire of man to understand what he/ she is made of and comes from. Thus, it appears to be against human nature to limit research into these topics, even though there may be no immediate application.

- The second example refers to the importance of intermediate steps in the gain of knowledge. At some, not too distant future, hESC cells may be generated independently of the use of embryos. Then, the ethical issues discussed here would become largely obsolete. We do not know whether this will happen, but encouraging scientific data indicate that it may become possible (see issue 32 on iPS). Still, we know one thing for sure: Without research in hESC cells and without the knowledge gained there from, this step would never happen! At present, hESC derived from zygotes are the golden standard by which all other ES cells are measured by as they come into being. We would not learn to reprogram other cells for therapeutic and scientific purposes, if we would not know what to reprogram them to. This progress via essential intermediate steps has happened dozens of times in the history of science and culture. We no longer inject people with extracts from bovine brain or porcine pancreas to treat dwarfism or diabetes. We would risk the transfer of retroviruses and infectious agents causing spongiform encephalitis (mad cow disease). Instead we produce clean recombinant human growth hormone and insulin. However, we would never have arrived there without the intermediate step of the natural product therapy. In the same vein, we no longer expose printers (type setters) to lead poisoning, as was common before the introduction of computerized and other "cold-type" printing techniques some decades ago, but - again - we would not have these modern techniques (and probably none of our culture at all) without a long period of printing by mechanical letter setting.

- In the long run, purely scientific progress often finds the most astonishing practical applications. In many cases, directed research would never have resulted in these discoveries. Without basic, non-directed research of the past, many practical applications of today would be unthinkable - and (as mentioned above) without basic research today, we will not solve the (yet unknown) challenges of the future (Solter, 2006). One of the oldest examples from the field of medicine are dissections of bodies. These were forbidden for about a millennium as "basic research that may violate the dignity of man or the respect for God". In the end, legalization and moral acceptance of this research facilitated progress in surgery and other disciplines that could never have been anticipated or even dreamt of before.

\section{Features of the discussion and the way of argumentation}

In the debate on hESC, high values are at stake. The discussion is not only based on the exchange and consideration of logical arguments, but it is also used to attract followers, voters and members (of parties, churches and research organizations). Accordingly, also techniques of manipulation, appeals to the unconscious and references to historical events are used. These need to be understood and dissociated from the factual debate.

\subsection{Issue 16: Historical and cultural aspects}

The approach to the use of stem cells is often influenced by the culture of a society and its dominant religion and church organizations. For instance hESC re- search is perfectly acceptable in Israel and also in relatively religious Moslem societies. Israel has a front role in hESC research and Iran for instance has generated its own hESC lines (Baharvand et al., 2004).

The Protestant Churches differ in their viewpoint, ranging from relative acceptance, e.g. by the Anglican Church to absolute rejection by others. The Catholic Church has an interesting history of defining the beginning of human life and moment of ensoulment, which moved closer and closer to the zygote as more biological knowledge was accumulated. The definition of Thomas Acquinas, which was used for centuries (and reaches back to ideas of Aristotle), referred to an ensoulment at day 40 after fertilization (day 80 for female fetuses). In 1869, the papal bull Apostolicae Sedis by Pius IX moved the time point of ensoulment and start of full human dignity to the stage of zygote formation. The new definition incorporated contemporary scientific knowledge (discovery of the biology of conception after the microscope was invented). At present, the modus operandi of the Catholic Church (e.g. the adherence to dogmata) slows further developments (i.e. adaptation of the time point of ensoulment) based on more recent scientific insights and progress in reproductive technologies.

More liberal Western countries such as Australia, Sweden, and the UK accept research with hESC including the generation of new hESC lines. This is also deemed acceptable in a number of Asian countries (India, China, Singapore, South Korea, Japan), but research is always controlled to varying degrees. The situation in the US is especially interesting. Federal funds cannot be granted for hESC generation for ethical reasons, but there are few limitations on research carried out with private funding. For instance, the US state of California is heavily sponsoring hESC research through raising of private funds ("proposition 71 ") and the formation of a privately founded designated hESC institute, the CIRM (Trounson et al., 2008).

Looking at this heterogeneous map, it is difficult to identify a clear ethical pattern. It is likely that cultural traditions 
and sometimes political influence of individuals (like A. Schwarzenegger in California) have at least as much impact as elaborate ethical considerations.

\subsection{Issue 17: The slippery slope issue}

Sometimes reference to historical roots can pose significant discussion hurdles - intentionally or unintentionally. One of the frequent "show stoppers" is the slippery slope argument ("Dammbruchargument" in German). This metaphor refers to a situation where the first small step irrevocably leads to an uncontrollable sequence of downstream events that end in a catastrophe or at least a difficult situation. With this approach it is easy to argue against anything, even though this "thing" may be acceptable on first sight to most people. The "trick" is, to link the first step to dire consequences further down the road, and make the connection of the steps look logical. Even though science has historically been seen mostly a steady stairway up to higher insight and better conditions of life for man, each of the new steps upwards has been called at some point by fundamentalist groups "the first step on a slippery slope downwards".

The slippery slope argument is then often reinforced by parallel references, whether they are relevant or not. Frequently encountered examples are references to euthanasia or other cruelties in the Nazi regime or the elimination of unfit children by the Spartans in old Greece. Another variant is that the blame is put on the acceptance of IVF as the first step on a slippery slope and the basis for the current hESC dilemma. From this argument, it is only a small step to seeing any sort of scientific and technological progress as such, as the first step on a slippery slope. The slippery slope argument is not necessarily a wrong argument in some ethical debates. But it is a dangerous argument, as it brings all discussions to a halt without real reflection on the problems and the potential solutions. Especially in the current hESC discussion, with widespread public acceptance of IVF and hESC generation and related methods having progressed so far, a slip- pery slope argument will only polarize the debate and prevent a constructive compromise. It is a matter of practical responsibility to also deal with unwelcome facts instead of just defining them away (see issue 24).

\subsection{Issue 18: Rhetorical variants}

All classical rhetorical means are used in the public debate on hESC research. Therefore, the vocabulary used frequently allows the identification of the standpoint of the speaker. If someone claims that he/she is for the protection of life, or belongs to a pro-life group (in US) and that human dignity must not be violated, one can conclude that the person objects to hESC research. Why is this so? Most researchers and supporters of hESC research would themselves fully agree with the statement, and they are also pro life (= supporting life). The problem is that these statements are not meant as statements of the content, but they are simple truism, that are usually used by objectors to put moral pressure on those accepting $\mathrm{hESC}$ research. It is an obvious accusation and attack that the others may not respect these principles. And use of such a truism often results in the assignment of moral superiority to those objecting to hESC cell research. Particular expressions are used to enhance fears by making things sound worse than they are (dysphemisms) or to make bad things look nice (euphemisms). A typical dysphemism was used 25 years ago, at the beginning of IVF. The procedure was not named as such but referred to in dysphemistic manner as bébé éprouvette (F), bambino in provetta (I), Retortenbaby (D), test tube baby (UK) - all expressions that evoked negative associations from A. Huxleys novel and that have now nearly entirely vanished, as the technology has become common and millions of children have been born and live amongst us.

Supporters of hESC research can be observed to use euphemistic words (such as the complicated term "pro-embryo"). This is done to avoid the use of the word embryo when describing the procedure of "cell line derivation". On the other hand dysphemisms are heavily used by objectors of hESC research. The members of the German parliament that objected to the new legislation on import of ES cell lines published a booklet "Against research consuming embryos", although it was absolutely clear that embryos have never been and will not be used for research in Germany, and that the change of the import law for ES cell lines would also not lead to more or less embryo consumption, neither inside nor outside of Germany. Extremist objectors even use the words "killing" and "murder" for the generation of hESC cell lines, and we have detailed in issue 1 why this terminology is inappropriate. The expression "therapeutic cloning", which is used to describe nuclear transfer, should also figure as a deliberate dysphemism, considering the fears and the relative lack of exact information of the public with relation to cloning and the negative image of the word. In conclusion, it is useful and highly advisable to agree on a common unbiased terminology avoiding any dysphemisms or euphemisms when entering into a public debate on hESC research or related issues.

\subsection{Issue 19: Different logics may apply}

To understand the discussion on hESC cells, it is important to recognize that depending on the viewpoint, different " $\log$ ics" may apply - and these different logics may all be correct. Thus, both sides may be right, even though they disagree, and acknowledgement of this situation should promote tolerance towards the other point of view. The correctness of different "logics" is not only based on different initial assumptions. It is also possible because what is colloquially called "logics of the argument" does not follow strict rules of deductive logics. Instead, the arguments used in public discussions are mostly built on chains of reasoning that include intuition, emotions and relatively non-compelling associations.

Pseudo-logics and syllogistic (i.e. an argument where one proposition is simply inferred from two premises) mistakes are very common, and they are acceptable when their use is involuntary, due to strong emotional involvement or due to a lack of formal training. However, the situation is 
different when logical mistakes are produced on purpose for manipulative reasons by persons skilled in the art of logic reasoning. A typical pseudo-logic line of argument would be the following: Statement 1: "We need to protect the weak". Right, it is a fundamental value of democracy to protect the weak (see issue 14). Statement 2: "Embryos are weak". Right, cells and embryos cannot lobby for themselves and they are vulnerable. Now different conclusion may be drawn from statements 1 + 2. Conclusion 1: "We need to protect embryos" is a sentence obeying the rules of syllogism, i.e. it follows logically from $1+2$. As a consequence of this conclusion, embryo protection laws were passed in many countries. An alternative conclusion also encountered during discussions is conclusion 2: "Therefore research on stem cells must be prohibited". This conclusion harbors several logical misconceptions. "Therefore" is a wrong term, as conclusion 2 does not result logically from sentences 1 and 2. The exclusive term "must" is also wrong. Prohibition of stem cell research would only be one of many possible ways to protect embryos. Without the words "therefore" and "must", the implication and relation of the major meaning-bearing words "stem cells" and "prohibited" is not defined. However, "prohibition" stands close to "stem cells" and therefore gives an erroneous (and manipulative) impression of a logical link (=pseudo-logics). A third misconception is particularly deceptive. Sentence 1 is "We need to protect the weak". It does not say "the weak persons", but in our mind we easily add "persons". However, if sentence 2 was "animals are weak", then the syllogistic conclusion 1 would be "We need to protect animals"... we leave everybody to their own thoughts here, but one implication is, that "Embryo protection" as in conclusion 1, does not imply that embryos are persons. However, in debates that are not logically clean this is often surmised. The rationale for the deliberate use of such pseudo-arguments may be the recruitment of followers for a certain cause.

Another typical pseudo-logical manipulation is the reversal of statements that cannot be reversed. For instance, "every person has been an embryo once". This is a universal statement that is always correct. It establishes a connection be- tween grown up people and early embryos and generates an emotional link, as everybody can refer to oneself as having been such an embryo. Once this state of mind has been set, the viewpoint is then reversed: "Thus, every embryo will be a person unless he/she is actively inhibited in this development" and "If every embryo will be a person, it also should be granted full human dignity". The reversal of this conclusion is logically just a rhetoric trick, and biologically not allowed (as detailed in issue 4), but this rhetoric trick is frequently used by $\mathrm{hESC}$ research opponents. It is similar to transforming "all cherry trees have been a cherry once" into "all cherries will become cherry trees...".

An argument mentioned in issue 7 (nidation) is also a pseudo-logical error. It is claimed that death of most blastocysts before nidation has no role in the continuity and potentiality discussion, as we also do not contest human personhood in situations where a high fraction of babies die after birth (as was common in most Western countries up to 100 years ago). There appears to be something logical in this argument, until one realizes that two entirely different situations are be- ing compared. In one case (death of babies), the personhood was already there before (!) death. Nobody would ever contest that. Thus death of babies is not related to the continuity discussion at all. In the case of blastocysts, the situation is entirely different. If one does not accept the purely religiously-based argument of ensoulment at gamete fusion, then continuity and potentiality between the blastocyst and a later human being must be established for the assignment of partial or complete personhood to the early form.

\subsection{Issue 20: The definition of ethical and unethical}

The fate of many new technologies has been to be first considered unethical and then slowly becoming less unethical and eventually becoming acceptable or even desirable. One wonders whether this is going to happen to hESC research, and what determines such changes.

One key factor is certainly whether there is demand and hence a market for this technology. Stem cell-based technology will most likely be broadly accepted if a successful application can be found, and it will vanish by itself, if this does

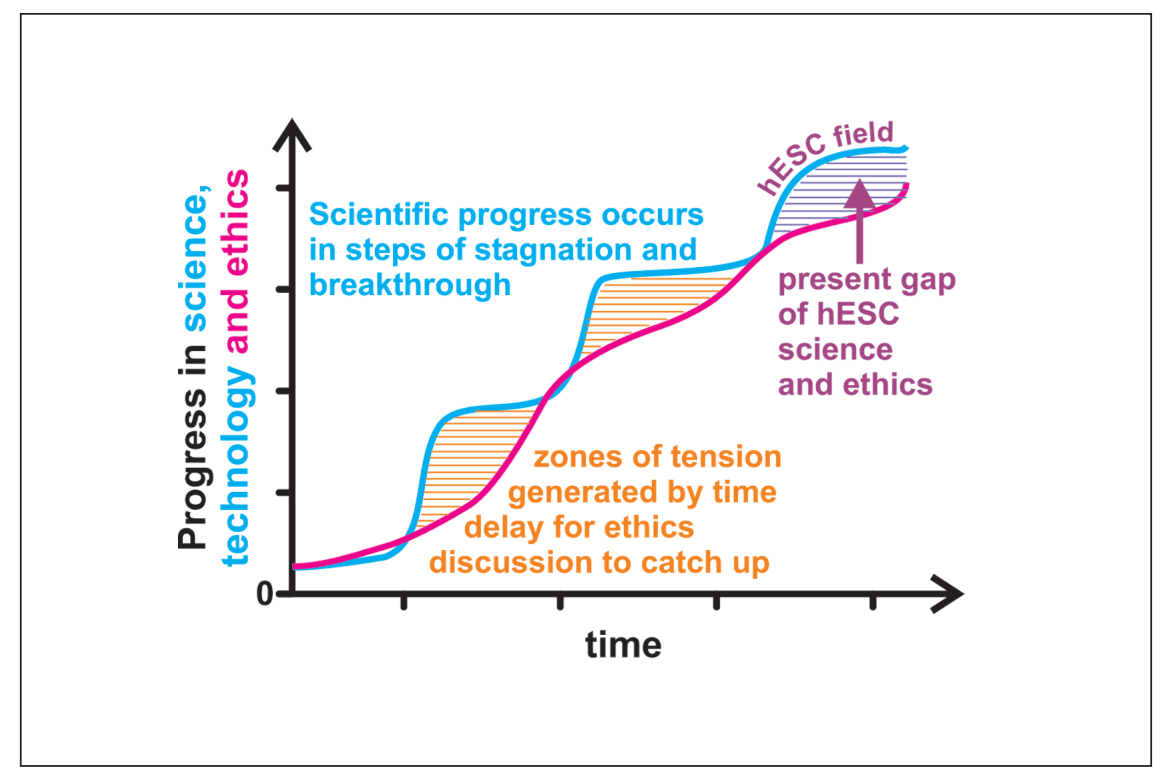

Fig. 4: The development of scientific/technological understanding and the maturation of the ethical debate

Scientific progress is shown to occur in steps (blue). Bioethics as academic discipline develops in reaction to scientific progress. The process of consolidation and progress in this discipline is smoother than in science (red). This creates zones of tension, when science advances into new areas where the ethical debate is not yet settled. At present we are in such a stage with respect to hESC research. 
not happen, for instance when it is competed out by another technology. Can the market really define whether something is ethical or unethical?

- Shift of attention: Possibly, we are observing only an apparent change. Scientific method is based on the principle of falsification (Popper, 1934). Thus it is straightforward to show that something is unethical (one single condition lacking). It is however much harder to show that something is ethical (all conditions fulfilled without exception). A single scratch in the image suffices to render it unethical again. With emerging technologies, many different societal and religious groups try their claws, and it is unlikely that there is not one or another aspect of the new technology that may generate ethical conflicts. With increasing success and establishment of the technology, it is more and more taken for granted and less targeted by ethical attacks. Thus it does not become necessarily more ethical, but the scrutiny and attacks diminish. An apparent change has taken place, but it only reflects a shift in attention. A typical example would be IVF.

- In addition to the shift in attention, the evaluation of what is ethical is dependent on the societal consensus, which changes with time and situation. Beating of children is an example where we have seen large changes in attitude e.g. in Europe. Or gluttony (overeating), which depending on the society, has been considered unethical (mortal $\sin$ ), neutral or positive. Terrorist laws restricting individual freedom are accepted as necessary or rejected as unethical, depending on the actual political situation and state of threat. Thus, it is common for ethical judgments to change over time and this will most likely happen for hESC research, once a beneficial application has been found (see balance of values, above).

- The above issues are theoretical considerations of what may happen to the public evaluation of hESC research. Furthermore, a general practical phenomenon can hardly be avoided: scientific progress often occurs in steps (Kuhn, 1962), i.e. not much happens for a while and then suddenly a new technology develops that pushes progress.
The ethical discussion of new developments, maturation of thoughts and incorporation into the existing framework follows different kinetics. It takes time, is more continuous and has to react to what is happening in science (Zoloth, 2002). As a consequence, ethical discussion lags behind during periods of rapid scientific change, and this generates controversies and discrepancies, which are in most cases resolved by time, as bioethics catches up again with the state of science. Presently, a scientific step is happening in the field of stem cells and it may be speculated that what appears so controversial today, will be in line with main stream ethical standards in 10 years time (Fig. 4 ).

\subsection{Issue 21: The right to be right}

If one accepts that different logics may apply and that ethics has a certain dynamics of its own, then there is a good basis for tolerance in the hESC debate. However, this situation and the potential for reasonable compromises are jeopardized, if different sides claim a natural right to be right. For instance the churches often claim authority in moral questions. Even more, they claim that religion is the only means to give meaning to life and to answer the question of why we exist. From this, it is only a small step to claim the right to define what is right and wrong for human beings attempting to live a meaningful life, and finally the absolute moral authority on stem cell issues is derived. In a democratic and pluralistic society, where members of different religions, and cultures coexist, such an attitude is not helpful for productive discussion. Scientists, on the other hand, claim authority on all technical knowledge and a superiority of technical knowledge over other forms of insight. Some of them tend to display a very narrow "technocratic" viewpoint devoid of social, religious or ethical aspects. This attitude must fail terribly, when it is applied to ethical standpoints. Things become worse, when the right to be right is used for accusations, such as churches being hostile to science and scientists doing things just because they are doable, no matter what consequences there are, or being pure utilitarians with no concern for the dignity of man. If these attitudes are avoided the whole debate can be brought to a more constructive direction. Most Western societies are built on the principle of pluralism, which forbids by itself the ethical hegemony of one group.

\subsection{Issue 22: Mistrust and irrational fears}

In order to settle the controversies around the use and creation of hESC, it is important to understand all the reasons that form a basis for objections. One of the reasons is an inborn fear or mistrust of complex and powerful systems that we do not understand intuitively, and that are out of our control. Scientific laboratories and what happens in them, behind their closed doors, are such a system for much of the public. Moreover, the topic of stem cell generation and use is often immediately associated with the topic of cloning and de novo generation of strange human-like beings. This has been a topic of horror since Mary Shelley's Frankenstein, H. G. Wells' Island of Dr Moreau and Aldous Huxley's Brave New World, and misconceptions and fears have been enhanced and promoted by dozens of Hollywood films. No rational argument will be strong enough to wipe away irrational fears due to new technologies.

However, some groups use this situation for their own agenda. In a complex world, that has become difficult to conceptionalize and understand, simple concepts are offered, and these are usually associated with a rejection of all scientific progress. This fundamentalism is no solution, but it is growing. The big Christian churches have a huge responsibility here, not to jump on this bandwagon and to offer the comforting simplicity of technology rejection as a solution to the intricacies and complexities of the world. What else can be done? The alternative approach is time, teaching and transparency. The more education, the more understanding. The more understanding, the fewer uncontrollable complexities. The more transparency, the fewer irrational fears. The broader the common knowledge, the less risk for individual and public opinions to be manipulated! 
Scientists especially must not forget that naked information needs to be transformed into knowledge and knowledge into confidence. Generation of confidence also requires experience, and both take time. It is important to realize, that this applies to highly educated scientists as well as to the general population. Most scientific revolutions have also been objected to by the other scientists of their time (otherwise they would not have been called revolutions), and only time has led to confidence and acceptance. With the emergence of hESC-based test systems, it is important to plan in advance for devoting time and creating opportunities to engage in public discussion. A full implementation of the technology will only make sense when its time has come, and society has matured to accept hESCbased test systems. Both promoters and objectors of hESC research should use the time for a constructive dialog.

\subsection{Issue 23: The question of opinion formation}

To understand the evolution of the debate on the use of hESC cells, it is useful to briefly look at some aspects important for the formation of opinions in general. From many examples (internet shopping, IVF - assisted reproductive technologies, heart transplants ...) we know, that what is commonplace today, used to be complex, unknown, dangerous and stressing only some years ago. Not only the external situation can change, but intuition and confidence grow with use and time. This means that one can naturally come to a different conclusion if one re-evaluates a situation now, as compared to some years ago. This sounds trivial, but has caused so many problems in the hESC debate (and elsewhere). For instance, certain members of parliament and of the protestant church in Germany had objections to the use of hESC lines in the 1990s, but were more open to accept a limited use of this technology in 2008. Conservative circles have called that change of attitude "moral inconsistency" and implied a lack of character. It appears difficult for these circles to accept that an ethical evaluation can change when the circumstances and understanding change. In an atmosphere where opinions have to remain fixed, compromise is hard to negotiate. What is the background for this attitude? In many countries, in and outside Europe, conservative circles are strongly influenced by the Catholic Church. In this organization, the principle of pluralism is not adhered to as strongly as in other cultural settings. The freedom of thought in this institution is naturally limited by dogmas that need to be adhered to, and by the belief in the infallibility of the opinion of the pope, which makes changes of opinion difficult.

\subsection{Issue 24: Practical responsibility}

An important issue determining the formation of opinions, including the one on hESC, is the link to responsibility and power. It is easy to object to anything that is ethically difficult, if one does not have to take the responsibility for the consequences of the denial. For instance, young people and youth organizations of parties and societal groups often object to societal rules and guidelines. Their attitudes and also their practical behavior often changes radically when they take responsibility in the function of managers and politicians. Then, they may come to different conclusions, because many issues with all their consequences need to be balanced. With this situation in mind, one has to take a closer look at the groups objecting to hESC research. Some opponents do not feel any difference in their lives, whether science advances or not. For them, scientific progress is not an important value as such or something that has importance for their lives. They either lack the necessary historical understanding and general insight, or they object to technological development in principal for a number of diverse reasons. Others are just innocently ignorant and according to the motto just pain, no gain, these must naturally come to a judgment that is critical towards the use of hESC. Also, an exclusive focus on the fate of the soul after death can detract from interests in science for the body before death.

Under this chapter of "practical responsibility" also a number of provocative thoughts shall be presented, not as fixed opinions, but rather as a stimulus and food for thought. To put it frankly, we may ask: does a tiny ball of 200 cells, without any neural system, and with no chance to become a human being (because its "parents" have decided so) really need significantly more ethical protection than the organs of an adult man (protected by the transplantation law) who had a motorbike accident? If we were less politically correct, we may go on to ask more generally, whether the concept of unconditional human dignity really holds in practice in its extreme interpretation as detailed under issue 11 , or whether it is an expression of the luxurious situation of our life combined with hypocrisy. Let's initially look at a single defined example to illustrate the thought: "triage". This is originally a military term (now also applied during major catastrophies, i.e. hurricane Katrina) used for the process of defining the wounded that should be treated after a battle, when only a limited number of doctors or amount of drugs is available. In practical terms, someone has to take this decision, even though everybody has basically the same right to be treated. In civil terms we find similar examples when someone decides who has a right to obtain a transplant organ. These are not active killing decisions, but it is accepted that the ones that have been chosen not to be treated will die.

In other situations, loss of human lives is knowingly accepted if the active decision to "send people into their death" is just sufficiently diluted by some random principle of who will actually die, or if it is balanced by other interests and values: One example would be the construction of huge physical structures that inevitably leads (or lead) to a significant number of deadly accidents (for instance, building the Gotthard tunnel took 177 lives, yet, we find it ethically acceptable to use the tunnel). Also, we are used to a death toll by car traffic of tens of thousands per annum without questioning the actual traffic regulations and driving our cars; all clinical studies conducted to introduce new treatments inherently carry a risk for the participants to be harmed or even die; military commanders sending troops to Afghanistan, Iraq, Falklands ... or commanders of fire brigades in charge of difficult tasks know that (statistically speaking) some of their crew will definitely be killed.

While we are using time and energy discussing the ethics of hESC research based 
on left-over IVF embryos, 750 million real people are suffering from hunger and more children die of its consequences in one day, than the total number of embryos ever used for research. Who takes care of the dignity here? Children should not go to school hungry, and hide their hunger because it is embarrassing. This happens in our own countries and is a violation of dignity of human persons, whose actual potential is being limited. We rarely have podium discussions and parliament debates on these topics. Why is this? Could it be that we have lost perspective? Could it be that we generate artificial problems about hESC research instead of solving real problems of real people?

\subsection{Issue 25: The bathtub function of embryo rights}

The issue of practical responsibility necessitates mentioning of a strange phenomenon. The so-called bathtub function - first high, then low, then high again. This is the protection status of the embryo in some countries, including Germany. Initially, fertilized oocytes are highly protected, by stem cell laws and embryo protection laws. Essentially, at this stage blastocysts are given an ethical and legal status that is almost comparable to a person. At 5-9 days of age, nidation starts and thus pregnancy officially begins. Now abortion becomes possible, and killing of the embryo is allowed, or at least tolerated. Several weeks (or even months in extreme cases when abortion of a fetus is medically indicated) later, it is forbidden again and the embryo is fully protected. Where is the legal consistency - and credibility of the practical legal framework - in this bathtub function? Moreover, it needs to be mentioned that killing of the embryo (after nidation) is explicitly allowed under certain circumstances. In many countries, the medical indication applies, i.e. the embryo may be killed if there is a danger for the mother, or if the embryo has no good chances to develop to a healthy child (which strictly speaking applies to all non-transplanted blastocysts by default). In the case of abortion, the issue of dignity is handled pragmatically and very praxis-oriented, and not as would be required by theory. Also, here the mother, and only the moth- er, carries full rights to decide over the fate of her potential future child. The situation becomes even more striking when one looks at so-called "criminogenic indications" as for instance under German or Polish law. If there is a possibility that the pregnancy is due to a rape, then the embryo may be killed.... How does this fit in with the claim of unconditional inviolability of human dignity?

\subsection{Issue 26: Intellectual property rights}

New technologies usually involve intellectual property rights (IPR). The issue of IPR is a potential ethical dilemma in the field of hESC-based test systems, and it is often an area of great insecurity for the research community involved. Intellectual property (e.g. inventions) is often protected by patents (i.e. a temporary, and nationally-limited right to prevent others from using it). A frequently discussed series of such patents $(\# 5,483,780$ and \#6,200,806) is held by the Wisconsin Alumni Research Foundation (WARF) and describes the culture and derivation of hESC and the cells themselves (Plomer et al., 2008). These patents are based on pioneering work by Jamie Thompson at the University of Wisconsin.

In general, both procedures and cell lines themselves can be patented. In both cases, it is important that something novel was done, and an inventive step was involved in the procedure. If a procedure (e.g. to make hESC) is patented, then also the product that was generated with this procedure is protected. This has a number of important practical implications that may be used as examples for other cases and to help clarify uncertainties in the research community:

- The WARF cells are patent protected in the US (where the patents are valid) even though the patents claimed only a process of generation and culture of the cells, and not the composition of matter directly.

- If someone else, in a country where the patents are not valid (e.g. in Germany or most of Asia) would use the "WARF method" to generate new ESC, this would not be a violation of patent laws. These cells would be free of the WARF patent. However, as the WARF method is a published, generally-accessible method, generation would also not be inventive and novel (if the WARF procedure is identically copied), and thus not patentable in the country were the new ESC are generated. Thus, it is likely that many ESC lines are not generally protected by patents.

- It is important to distinguish the protection by patents from ownership of the material. A cell line can be owned by the producer according to national legislation on private property. If such material is given away, a material transfer agreement (MTA) can be negotiated between the recipient and the owner. This has nothing to do with patents and IPR, but is a purely private contract on conditions of use of the material. "Material" is used here in a purely legal sense. The issue on how far something derived from human beings can be "owned" and "traded" is ethically complex and does not only involve hESC. One has to bear in mind that in many areas marketing of human cell lines, tissues and other human material has had a long tradition.

- The owner of a patent can allow others to use the invention (e.g. hESC line) under certain conditions. This permit is called a license and can be exclusive or non-exclusive. For instance WARF is non-exclusively allowing other companies to use their cell lines and technology for commercial purposes against a license fee of e.g. 125,000 \$.

- Often MTAs also contain rules on how the intellectual property rights are handled, when an invention is made while the "material" was used or because the material was used, but this has nothing to do with patents on the material (hESC) itself. It is a purely private agreement between the parties involved and to be freely negotiated.

hESC pose a particular ethical problem for the handling of intellectual property rights, as they border upon the question of how far life, and especially human life should be patentable. In Europe, Article 53(a) of the European Patent Convention (EPC) precludes the patenting of inventions whose exploitation would be contrary to "ordre public" or morality. One of the most prominent examples of application of this paragraph is the "Ed- 
inburgh" patent (European patent No. 0695351, owned by the University of Edinburgh after it was granted in 1999). The patent concerns a method of genetically modifying animal stem cells so as to give them a survival advantage over unwanted differentiated cells. The method can help to culture and isolate desired stem cells. When the patent was granted, it was overlooked that the term "animal" explicitly included humans, and the patent could be interpreted as to include human ESC. After massive protests initiated by Greenpeace, the patent had to be modified to exclude humans. Also the WARF patents are currently a test case for European patenting policy. They were refused on basis of article 53(a) EPC, and the question of whether human embryonic stem cells are patentable in the EU is currently pending before the Enlarged Board of Appeal of the European patent office. Countries like the UK claim that patents must not be refused on moral grounds when there is no clear consensus among the European states on the morality of stem cell research and patenting, as this would impose undue restrictions on countries where hESC research is ethically acceptable and allowable.

The scope of the ethical issue of stem cell patenting is more complex than it may appear on first glance. Most patent applications do not refer to the cells (i.e. the "composition of matter" of particular human material) themselves, but to methods that can be applied to such cells, or their precursors or their derivatives. The arising problems are illustrated by the following case: In the US for instance human tissue is not patentable (35 USC $\S 101)$, but the method of making clones of genes or cell lines is absolutely patentable, as are the cell lines themselves. The argument is that clones and cell lines are not the original human tissue, but a copy thereof, or obtained by a technical procedure. As hESC do not exist in nature, but only in cell culture dishes, they could also be deemed patentable (Hansson et al., 2007) A similar line of argument is e.g. also found in the German patent law (PatG §1a). A more specific restriction with respect to the use of stem cells in the US is Rule 23(e)(1) which prevents patenting of a "stage" in the formation and development of the human body.
However, it is argued here, that the rule applies to totipotent stem cells only, because these have the potential to develop into all the cells necessary for human development. On the same grounds multipotent ESC are excluded from that rule, as they are capable of differentiating into all cell types that make up the human body but are not capable of giving rise to a human being. The key issue is that totipotent cells were initially required for the generation of hESC, but the ultimate decision is still pending in the US.

In contrast, a clear decision to this respect has been taken in Germany, using patent No. 19756864 of O. Brüstle as a test case. In the "Brüstle case", the patent office severely limited the scope of the patent because of ethical concerns. The patent claimed methods to produce neurons and neural precursor cells from stem cells. It did not comprise claims on the generation of embryonic stem cells and mainly described an application of existing hESC. Nevertheless the reason given for the restriction of the claims was that at some point hESC had to be generated for the patent to make sense. Patenting of technology in this area should be prevented in order to preclude commercial and economic incentives for the destruction of embryos. The field of new methods for stem cell differentiation (as e.g. the Brüstle patent) and secondary stem cell use is highly active and it remains to be seen whether patents in this area will stand scrutiny and remain valid in Europe and its individual countries.

\subsection{Issue 27: Commercial aspects}

The commercialization of hESC is an ethical issue that disturbs many people. It is often claimed that patents in this area prevent the rapid development of test systems and therapies for the benefit of the general public. This is a particularly touchy issue, as the patenting involves cells that can at some point be traced back to potential human life stages. On the other hand, patenting is commonplace in many other research disciplines with potential benefits for public health. In fact, history has shown that the possibility to protect important inventions by patents has often been a pivotal basis for the development of new therapies. The translation of basic hESC research into practical applications is an extremely expensive enterprise with a high attrition rate and many risks of failure. Lack of patent protection would deprive pharmaceutical companies of their incentive to engage in development of new hESCbased models, test-systems and therapies. It is interesting to have a closer look at the fate of the above described cell lines covered by WARF patents. These have been given to more than 400 academic labs basically free of cost, as long as they are used for basic research and not commercialization. This example illustrates well that academic research is not necessarily limited by patents.

Many people are particularly concerned when potential therapies are being patented directly. This appears unethical on first sight, but requires a differentiated approach. For instance, we are well accustomed to medical instruments and drugs being heavily patented areas, and know that, also on the ethical side, usually the benefits of protection are greater than the disadvantages. The same applies to many diagnostic test kits. For instance $\S 2 \mathrm{a}$ of the German patent law excludes patenting of surgical or therapeutic or diagnostic methods, but not that of the material used for above procedures. Thus, an hESC-derived product, which forms the basis of a therapy, or the procedure to generate this product, can be patented, unless it conflicts with the rules of the embryo protection law (and its reflection in $\$ 2 \mathrm{PatG})$.

A highly important issue for the practical use and commercialization of hESC based technologies and test systems are so-called "reach-through claims". This problem often creates large insecurity for academic researchers, who have no particular skills at defining their freedom-tooperate. Even for companies with experienced legal departments, this can be a mine-field and it becomes unclear whether one is performing illegal research. Reach-through claims seek to protect things which have not yet been discovered by an inventor, but which might be discovered in the future by making use of their invention. For instance, someone discovers and patents a good method to generate neurons from $\mathrm{hESC}$, and then 
makes claims to include compounds and therapeutics discovered with the use of such neuronal cells. These are not allowed in patent law, but frequently found in material transfer agreements (MTAs). A typical example would be that an $\mathrm{hESC}$ line is transferred and all rights are claimed to all derivatives of these lines, e.g. with certain reporter constructs, or even to the constructs themselves if they have been developed with help of the cell line. Such claims do not usually derive from patented intellectual property rights, but they are purely private agreements fixed in the MTA. With regards to patenting inventions, based on other patented inventions (e.g. a new toxicological test system based on the use of patented hESC cultures), there is no basic rule preventing this - indeed this is commonplace and independent of whether the basic patent was licensed or not. This situation has to be distinguished from the frequently found situations that indeed many technologies and tools applied to hESC are patented (media, growth factors, plasmids, constructs, ...), and if the researcher employs or even wants to commercialize these, license agreements will become necessary.

\section{13 Issue 28: Secondary interests}

The discussion of ethical aspects of ESC research would be incomplete without considering that certain groups use the discussion for their own purpose and goals, which may have nothing to do with hESC themselves. Alternative motives for rejecting hESC research may be the gain of voters and supporters for politicians and fundamentalist religious movements. Also a general technophobia would be a motivation that is resistant against any type of argument. On the other hand hESC research may also be promoted not for its own sake, but to improve career chances and income of certain scientists and doctors.

\section{A broader view}

Human ESC are only one type of stem cells. If they can be easily substituted, why take the trouble, and why get ex- posed to an ethically difficult situation? To allow for some judgment on these issues, some of the alternatives are briefly described below.

\subsection{Issue 29: New cell lines}

Bringing hESC into clinical use faces great challenges, such as for instance providing $100 \%$ pure cell populations, and guaranteeing safety in terms of contamination with animal products, viruses or tumorigenic cells in the final potential cell therapy product (Hentze et al., 2007; Vogel, 2005). In this context it is important to note that almost all currently existing hESC lines have been derived under conditions that do not follow the guidelines of good manufacturing practice (GMP). For this reason, they will most likely never be clinically applicable in most countries. Furthermore, these cell lines were in contact and are therefore potentially contaminated with diverse animal products or viruses. The methods and culture conditions to derive the first hESC lines were adopted from what was known for mouse embryonic stem cells. Therefore, primary mouse fibroblasts, generated under uncontrolled non-GMP conditions and possibly contaminated with unknown pathogens, were used as feeder cells. Moreover, hESC have been traditionally grown in the presence of bovine serum and some have been treated with non-GMP grade enzymes such as trypsin from porcine origin. Therefore, the current hESC lines grown under these conditions will most likely not meet the stringent standards for cell therapy products in the USA. The situation may be seen slightly differently in Europe at least for pilot trials for proof of principle. Presently, some attempts are going on to "clean up" existing cell lines. However, should broad therapeutic applications ever become reality, new cell lines would most likely be required. Also for test systems, adherence to good cell culture practice guidelines (Rispin and Stitzel, 2006; Gstraunthaler, 2006; Balls et al., 2006) would require highly defined cell lines. Several steps have been taken in this direction, e.g. by Cellartis (Sweden) or ESI (Singapore) or Geron and ACT (USA). For instance ESI have produced six clinical-grade hESC lines (Crook et al., 2008). These lines underwent stringent pathogen and sterility testing and represent, in principle, suitable raw material for future highquality test systems and therapeutic applications.

\subsection{Issue 30: So-called adult stem cells}

Research in the area of adult stem cells has been ongoing for many decades. Therefore the volume and quality of research output, as well as the number of laboratories involved is orders of magnitude larger than in the small field of hESC. The term "adult stem cells", as it is used in the hESC debate, describes a large group of different cell systems. In biological terms, adult stem cells are easily defined as being derived from adult human beings. However, in listings of alternatives to hESC, often all cells that are not hESC are grouped together. For instance, human fetuses (embryos with developed brain; obtained from abortions) can be used as sources for such non-hESC, "adult" stem cells. This is not a rare case, but historically one of the major sources of stem cell therapy besides bone marrow. The cells are still used frequently therapeutically, although in many cases the value of such treatment is medically doubtful. Therapeutic centers are mainly located in Asia and former member states of the Soviet Union (Baker, 2005), but they are also used e.g. for treatment of Parkinson's disease in Europe and the US (Hall et al., 2007, Li et al., 2008). These fetal cells are not hESCs and are multipotent (for instance, a haematopoietic precursor can generate blood cells and liver cells, but not neurons), but not pluripotent. Here, nomenclature confusion becomes a real issue, that also has an effect on the ethics discussion. The fetal stem cells (colloquially often called embryonal stem cells) are certainly not adult stem cells and certainly not free of ethical concerns, while the hESC are derived from blastocysts (which are not embryos in a narrow medical sense).

The most common sources for adult stem cells are the bone marrow and blood. Such cells are so-called multipotent or oligopotent stem cells, or hematopoietic 
precursor cells, because they can only form a few cell types within their natural lineage. In fact, bone marrow transplantations have been performed as early as 1959 by a team lead by E.D. Thomas, and this procedure represents the oldest form of stem cell therapy.

Another more recently harnessed source of "adult" stem cells is the cord blood at birth. Hematopoietic cells from cord blood have indeed proven beneficial, especially for restoration of the blood-forming system (Broxmeyer, 2005). Although this area is still in its infancy (Schoemans et al., 2006) commercial companies have developed a flourishing business model based on the moral pressure on parents to have cord blood from their newborns frozen. This situation is an ethical issue in itself, as nobody knows in how far these cells can still be used in 70 years time, when they may be needed. These cells are difficult to expand (one requires currently more than one cord blood specimen to treat one diseased adult), they have a limited potential (currently they are only useful to treat hematological malignancies - such as leukemia) or bone marrow failure -, and it is unclear whether treatment with own cord blood cells is always a good solution to treat genetic disease, as these cells are likely to carry the same mutations that induced the disease.

The use of the above adult stem cells for therapy has been quickly progressing because clinical trials can be performed without requiring FDA approval when cells are not greatly modified and when they are used to substitute tissue within their natural differentiation line (autologous transplants). For instance, when cells are cultured for less than $24 \mathrm{~h}$ before their homologous clinical use (e.g. bone marrow stem cells used as bone marrow substitute), the procedure is not regulated as a drug but as a surgical procedure by the FDA. However, adult stem cells that need to be expanded in vitro and modified fall under the same stringent rules as $\mathrm{hESC}$, and their application has been very limited. As adult stem cells are far more limited in their potential to divide (in contrast, hESCs can divide indefinitely), production of large amounts, in addition to all the required safety examinations, is a serious technical obstacle. Despite the clear fact that adult stem cells (different from the hematopoietic system) have a limited growth and differentiation potential, a lot of erroneous information has been spread throughout the literature on the apparent global therapeutic usefulness of adult stem cells (Smith et al., 2006). For instance, it has been claimed that bone marrow and hematopoietic cells may "trans-differentiate" to form other cell types not within their normal developmental lineage. However, it has been shown that such findings were, at least in parts, artifacts (Nygren et al., 2004). Also, it has been demonstrated that adult stem cells are inefficient, or in some cases even dangerous, in settings where hESC-derived cells looked promising (Breitbach et al., 2007; Kolossov et al., 2006). A more recent concern is, that the potential of adult stem cells may be even more limited than believed earlier. For instance in the intestine, the tissue if formed by different, non-overlapping stem cell populations (Sangiorgi and Capecci, 2008). The most advanced area of adult stem cell use at the moment concerns so-called mesenchymal stem cells, multipotent (not pluripotent) stem cells that may form bone, cartilage and connective tissue. There exist ample sources for these cells, e.g. from fat tissue obtained by liposuction, so that in vitro amplification is less of a problem. Also adult neural stem cells are being explored for the formation of neural tissue. In this case, availability of the cells is a seriously limiting factor, as is also true for cells from pancreas to heal diabetes, or cardiac muscle stem cells for heart repair. Except for bone marrow transplants which have a firmly established place in the repair of bone marrow, the present state of the art of stem cell applications can best be described as a race of different rescue teams in a very difficult landscape. All teams (hESC, fetal stem cells, adult stem cells, etc.) use different approach strategies and are still very far from the spot of the accident. So far, and with so many difficulties in between, it cannot be decided who will make it at all. In this situation, it appears unwise to exclude one of the important teams (hESC) early in the hope that the others may make it.

\subsection{Issue 31: Technological alternatives: cells obtained during pre-implantation diagnostics}

It may be interesting to review also other alternatives for generating pluripotent stem cells (Johnson, 2008). One approach stems from the area of pre-implantation genetic diagnosis (PIGD or PGD). When the zygote has divided 3 times and it reaches the 8-cell state (see Fig. 1), all eight cells are still totipotent and usually would form one embryo. However, each individual cell (called a blastomere) alone would be sufficient for full development. Therefore, when the Morula splits accidentally at this time, monozygotic twins would form. It is nowadays technically possible to remove one of the blastomeres for PGD without destroying the embryo or inhibiting its development to a human being. In some countries, this procedure is used for genetic diagnosis and early sex determination, which bears huge ethical problems, in particular in countries like China (Thomas, 2006). This technology is legally forbidden in some countries, including Germany.

It was recently shown in mice that a blastomere could be removed to generate an ESC line at this early stage, and the embryo continued to developed (Chung et al., 2006, Teramura et al., 2007). Similarly, it was shown that a hESC line could be generated from an individual human blastomere (Klimanskaya et al., 2006), and moreover it was shown for a human 8-cell morula that a hESC line can be generated, while development of the embryo goes on at least to blastocyst stage (Chung et al., 2008). This technology clearly avoids a lot of objections against the classical way of generating hESC. As the embryo is not killed, it may indeed be ethically acceptable to the Catholic Church, if it is proven that the chances for a successful pregnancy are not reduced by this method. This is, however, not clear at the present state of art, as the procedure requires poking a hole into the zona pellucida. Therefore, such embryos thaw e.g. with more problems after having been frozen. One may ask why one should run the danger of jeopardizing the life of a wanted child, while millions of blastocysts are available in nitrogen tanks. Another concern (which is about to 
become reality already now) is that normal fertile couples may chose this technology of assisted reproduction without direct need (Johnson, 2008), and mainly in order to provide their child to-be-born or sibling with a hESC line to provide "spare parts" that may be required later.

\subsection{Issue 32: Generation of stem cells by re-programming: iPS}

Reprogramming is the buzz-word of the year. What does this concept imply, how can we imagine differentiation and dedifferentiation? Since it was shown that certain adult cells could be de-differentiated (re-programmed) to behave like hESC in 2006 (Takahashi and Yamanaka, 2006), this concept has had a profound impact on the stem cell field. This is because this method could provide a way to generate hESC-like cells without requiring blastocysts, and moreover, autologous ("own") hESCs could, in theory, be generated from each individual for own therapy (Cyranoski, 2008).

To understand the re-programming, let's try to understand the process of cellular programming and of "stemness". The genome could be seen to contain a large number of "songs" (of genes). This is like the iTUNES store. However, not all of these songs are active. Only a defined set is usable. This is like the individual iTUNES library. Each type of differentiated cell (a neuron, a heart cell, a liver cell, ...) is like a particular iTUNES library on your computer or iPOD. Likewise, ESC do not have all songs available, but again a defined set. This set of songs defines that they are stem cells and not other cells. Thus, their particular iTUNES library defines their "stemness". Re-programming of a somatic cell (=of any cell in the body which is not a stem cell) is like sending one's entire iTUNES library back to the store and then downloading the set of songs that defines "stemness" as new library.

It was indeed shown first for murine cells in the lab of Shinya Yamanaka that reprogramming of mouse skin cells to ESC-like cells is possible (Takahashi and Yamanaka, 2006). These cells were called induced pluripotent stem cells (iPS) and were obtained by the simple genetic transfer and expression of four genes coding for the proteins Oct4, Sox2, $\mathrm{c}-\mathrm{Myc}, \mathrm{Klf} 4$. These four proteins are known transcription factors (i.e. regulators of gene expression themselves) that are highly expressed in hESC and are all well-characterized indicator for pluripotency in hESC. Obviously, the procedure was only possible because of the extensive experience with the handling of stem cells and the profound knowledge on their control. iPS cells could never have been generated without previous $\mathrm{hESC}$ research, and the experience with human hESC was the basis for the recent production also of human iPS (Takahashi et al., 2007; Yu et al., 2007). Although this is a milestone in stem cell research, it is important not to forget that for the generation of these cells, new genes are being expressed, and at least two of them are oncogenes (cancer-inducing genes), although later on it was shown that one of the oncogenes, c-Myc, is in fact dispensable in the generation of iPS cells (Nakagawa et al., 2008), and most recent data from the Smith and Schöler laboratories indicate, that possibly only Oct4 is absolutely required. However, one needs to consider that the genes are integrated into the genome of iPS cells, which may pose a risk as this can theoretically disrupt the function of other genes. Therefore, a long-term goal of some laboratories is to generate cells that transiently express the crucial pluripotency genes and then differentiate these cells as long as they are pluripotent (Nakagawa et al., 2008).

Obviously, it will still take a while until it is clear whether the iPS cells can ever be used therapeutically and whether all the reprogramming is indeed correct. Within the picture of iTUNES: some of the own song files that are moved back to the store, may be modified (possibly contain a virus or deletions), and some of the new songs downloaded for the stemness library, may have been modified in the meantime by the store (e.g. not be available anymore, or be only available in a different version or recording). Up to now, this method appears very promising on different levels: It was shown that the markers of hESC and iPS were more or less identical (Lowry et al., 2008; Wernig et al., 2007), and that at least murine iPS could be used therapeutically and form germ line cells and chimaeras (Hanna et al., 2008; Wernig et al., 2007). How the oncogenes and their vectors (the viral gene fragments carrying the genes into the cells) behave on the long run, and whether the genetic stability is the same as in hESC will need to be established. With iPS cells, we deal with a potential alternative to hESC, which needs to be observed closely and which would resolve many of the ethical issues about present hESC. Perhaps, reprogramming can be achieved in the future with the corresponding proteins directly (instead of the genes) and thus, more safely. If the potential of iPS cells holds true, we are dealing with a medical and technological revolution that may bring the second Nobel price to the field (after the one given 2007 to M. Capecci, O. Smithies and M. Evans) and hESC may become nothing more than a short, intermediary - but crucial - chapter in the history book of science.

\subsection{Issue 33: Nuclear transfer and ... human cloning}

Cloning is the horror word of the field, although its everyday application is fairly innocent. Cloning means nothing more or less than copying something in a biological system. Putting plant cuttings into the ground and growing blackberries from them is for instance a cloning progress. What people are afraid of is cloning of human beings, and this fear has led to objections to assisted reproductive technologies (e.g. in vitro fertilization), gene technology, biotechnology, and now hESC research. All of these have been wrongly associated with human cloning and it has not been stated clearly enough that it is at present technically impossible to clone a human (reproductive cloning), even if one wanted to. It will therefore not be dealt with further here as it has been discussed extensively elsewhere (Maio, 2006; Tannert, 2006).

However, a technique sometimes called therapeutic cloning can play a role in the hESC field. Therapeutic cloning is a misleading circumscription of a biological technique correctly called somatic cell nuclear transfer (SCNT). This technique starts from an oocyte which is in a state of being about to be fertilized, i.e. a cell with a high potential to develop further into 
totipotent and then multipotent cells, but with a nucleus that has only half the normal set of chromosomes and needs to fuse with a sperm nucleus to become complete again. One can circumvent the requirement for fertilization and fusion by removing the oocyte nucleus and inserting a complete nucleus from an adult cell (from a skin cell for example) with the full chromosome sets. This way, something "like a zygote" is created without fertilization. If it is brought into a culture environment that mimics the state of "post-fertilization", the zygote may start to divide and grow and eventually form a blastocyst (French et al., 2008). Theoretically, hESC lines could be created at this stage, but have not yet been reported. Possibly, the technology will not develop further. If the iPS technology holds what it promises, it will be easier to apply than SCNT.

The advantage of this technology would be that hESC lines may be generated for each individual (immunologi- cally matched) without ever touching the classical embryo stage, provided enough oocytes were available. However, the SCNT is associated with ethical and technical problems which are entirely unrelated to the cloning aspect. There is no unlimited availability of human oocytes and the oocytes themselves are heavily protected in many legislations. Oocytes and sperm are so-called gametes, and e.g. in Germany strict rules apply to handling and modification of gametes (embryo

\section{Box 1: Glossary of terms and abbreviations}

Blastocyst: "Early embryo", thin-walled hollow structure with about 200 cells containing the ICM (inner cell mass) and an outer rim. The blastocyst as a whole is totipotent, but its individual cells in the ICM are pluripotent.

Blastomere: One of the 8 totipotent cells of the early ( 8 cell stage) embryo.

Chromosomes: Long threats of DNA. They contain all genetic information. Each human cell contains 23 different chromosomes. Somatic cells always contain two sets $(2 \times 23$ $=46$ ) of chromo-somes (maternal and paternal). Gametes only contain one set.

Cryopreservation: A process of preserving and storing cells (such as oocytes, sperm, or blastocysts) by freezing them, typically at minus 196 degrees Celsius in liquid nitrogen. DNA: Nucleic acid coding the "genetic information" by a code based on the sequence of 4 different chemical structures (= nucleotides).

Embryo proper: Parts of the blastocyst that form the real embryo; other parts form e.g. the placenta.

Epigenetics: Biological changes or information which is not encoded in the nucleotide sequence of the DNA. E.g. changes in gene expression (and protein content) induced by environmental factors, such as the position of a cell within an organism, by toxins or drugs.

FDA: Food and Drug Administration, agency in the US responsible for the safety regulations of foods, drugs, vaccines, etc.

Gametes: Oocytes and sperm are gametes, i.e. cells that can recombine to create the first cell of a new organism. Gametes differ from somatic cells in that they usually only contain one set of chromosomes.

Gastrulation: An early phase in embryo development that leads to the formation of the initial primordial tissues.

GMP: "Good Manufacturing Practice", a term that stands for a high standard of control during the manufacturing of foods and drugs. hESC: Human embryonic stem cells.

ICM: Inner cell mass, pluripotent cells within a blastocyst, which form the "embryo proper" and from which hESC can be derived. In vitro: In cell culture, in a plastic dish, or in a test tube as opposed to in vivo (in an organism).

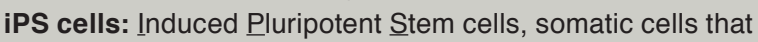
were rendered pluripotent by the introduction of certain factors.
IVF: In vitro fertilization, a method to fertilize oocytes outside the body, followed by re-implantation of the early embryo.

Mesenchymal stem cells: Multipotent stem cells that can form bone, cartilage and connective tissue.

Morula: Early embryo, round blackberry-shaped solid cell mass, surrounded by the zona pellucida, emerging several days postfertilization, developmental stage preceding the blastocyst.

Multipotency: Capacity to form a set of different cells (e.g. all blood cell types), but not all cell types.

Nidation: Implantation of the early embryo (blastocyst) into the womb.

Nucleus: Structure of the cell where the chromosomes (genetic information) are stored.

Oligopotency:Capacity to form some closely related cell types (e.g. B and T lymphocytes), but not all cell types, e.g. in an organ. Oocyte/Ovum: "Egg", a cell carrying one set of chromosomes from the mother and the capacity to develop to an embryo when it fuses with sperm.

Pluripotency: Pluripotent cells can form any known cell type such as liver cells, muscle cells, neurons etc., but they cannot generate a whole organism because they are lacking the capacity to form a placenta.

Reprogramming: Induction of epigenetic changes in a somatic cell, to transform it into a stem cell. The somatic cell obtains "stemness", but the DNA remains the same.

Somatic cell: Cells forming all the tissues of an organism and containing usually two sets of chromosomes, as opposed to germ line cells (gametes) that contain one set and are the basis for sexual reproduction.

Stemness: The characteristics that define a stem cell, i.e. of an undifferentiated cell that is able to multiply indefinitely and that is at least multipotent (can differentiate into other cell types). Totipotency: Only a zygote and the blastomeres of the early embryo (up to 8-cell stage) have the capacity to form all know cells types as well as a whole organism, as these cells are able to form a placenta.

Zona pellucida: A membrane structure surrounding the early embryo from zygote to late blastocyst stage, degenerates around day 10 post-fertilization to facilitate nidation.

Zygote: Fertilized egg (oocyte), a cell carrying the genetic information of the oocyte plus the sperm $(n=2)$. 
protection law), which also explicitly prohibits cloning. In the UK, even the use of animal oocytes is allowed as recipients for human nuclei. The product, which is termed "human-animal chimeras" was legalized in May 2008. However, the use of such chimaeras is restricted to a defined set of applications in basic science. The different legislations, even within the EU, demonstrate how ethical issues are judged differently in its member countries.

\subsection{Issue 34: Playing with definitions to generate alternatives}

The above chapters $(31,32$ and 33) demonstrate that rapid developments of technology can create new problems faster than they can be resolved in an ethical debate. Therefore, some scientists tried to solve the issues by technical approaches. Whether this is really a way out of the dilemma or rather a dead end remains open. However, the example of altered nuclear transfer illustrates well the complexities of the ethical debate and the problems that arise when one sticks too closely to definitions.

Altered nuclear transfer is one of a number of ways that have been designed to produce cell lines without the requirement of potentially viable zygotes (= "embryos"). One such approach is the introduction of a genetic defect preventing implantation, into an oocyte. For instance a defect in the gene for $\mathrm{Cdx}-2$ prevents development of the embryo (Meissner and Jaenisch, 2006). A zygote could be formed, but clearly lack the potential to ever become a human being. A hESC line may thus be derived from such a disabled pre-embryo without any danger of "embryo consumption" or "embryo killing". Although this is a scientifically elegant approach, it is not free of ethical concerns (because for instance an oocyte is being used, and in particular genetic manipulation of oocytes is forbidden in some countries) and the procedure is dangerously close to a slippery slope of double moral and political correctness that can end in complete ethical confusion without bringing a significant practical benefit.

An approach that appears more realistic is based on the morphological evalu- ation of embryo quality for implantation in the IVF procedure. Some embryos are judged to be of too poor quality to establish pregnancy. (However, in Germany it is not allowed anymore to undertake a positive or negative selection at the embryo stage. The selection must have taken place at the pronucleus-stage.) New methods allow generation of hESC from such embryos (Lerou et al., 2008a,b). This procedure should reduce the ethical concerns of those objecting to hESC line generation, but the situation is too new to have been thoroughly discussed. It needs to be mentioned again (as detailed above) that also frozen embryos that have been used in the past for hESC generation were only used after informed consent of the donors and often because they were of poorer quality than the blastocysts used for induction of pregnancy. The reason for their generation was IVF (and not research) and they were eventually used because they were not wanted anymore for implantation - and thus had no potential to ever develop to a human being.

A dilemma of the reverse form can be created, when the embryo definition is changed without adaptation of other rules affected by it. For instance in Switzerland, a recent law ascribes full embryo status to zygotes only $24 \mathrm{~h}$ after fertilization. This has strange consequences on the generation of hESC. Zygotes that were frozen years ago (before this law was passed), cannot be used for the generation of cell lines anymore, as they now are by definition no embryos anymore. By thawing them and keeping them in the culture dish, they would reach an age of 24 hours and then be considered to be embryos generated for research. A related situation is found in Scotland. There, failed oocytes (with no potential to develop) can be used for research. If such an oocyte is fertilized to generate a $\mathrm{hESC}$ line, this line is ethically unacceptable in most other countries, because its source has been an embryo "generated for research".

\subsection{Issue 35: Problems to come}

Ethical problems related to hESC are only the tip of an iceberg if one takes all the new developments into account. Until last century, humans were procreating exclusively in natural ways, according to an ancient biological program. Now, many new technologies related to the early phase of this program are arising, with potential benefits, but also huge risks for misuse. Ethical dilemmas do not only arise from different viewpoints within one society, but also from the largely differing legislations in neighboring countries. For instance bovine-human chimeric clones were legally produced in the UK, while such a process would be unthinkable, even for pure human clones in middle European countries.

The embryo definition is highly problematic already, but it will become even more complicated in the future. For instance, oocytes can theoretically develop without fertilization, if their nucleus is triggered appropriately. That this process of so-called parthenogenesis works also in practice, is seen in many plant and animal species, but not naturally in mammals. However, Japanese researchers have already created Kaguya, a fatherless mouse, that breeds normally (Moore and Ball, 2004). In 2004, a Korean researcher produced a parthenogenic human embryo by accident, as revealed only three years later, when an American group published the intentional production of purely parthenogenic human stem cells (Revazova et al., 2007, 2008). If such cells are used to generate blastocysts, is this an embryo? The definition of the fusion of the gametes becomes useless in this case.

Another issue for the near future is the generation of gametes from hESC. As $\mathrm{hESC}$ are multipotent, it is just a matter of time until high quality gametes (oocytes and sperm) can be generated in a robust way. We have seen ways (issues 31, 32 and 33) to produce hESC or cells that closely resemble them (iPS) by methods that do not use embryos (blastocysts) and thus should not be of the same ethical concern as classical hESC. What if gametes are produced from such cells and they are used for fusion with one another to generate a zygote? How would we handle the definition of parents in these cases? How would we handle cross-fertilization between different hESC lines by this method, to generate new lines with new genetic properties, some of them important as disease models, others also with a potential for misuse? 
Some may be frightened by these thoughts, others excited about the new opportunities, for instance for understanding human disease or to test drugs and chemicals on human cell systems instead of animals. Some may react in more fundamentalist ways, blocking any first step into these directions, in a hope to avoid the threatening and growing avalanche of future problems. Others may carefully explore what good can be done with new technologies. In the end, we have no ideas whether we will indeed rationally control what will be happening. In the past, need and applicability drove the acceptance or rejection of new technologies - completely independent of ethical issues, collateral damage, imminent threat, reason or brilliance of the idea. In the end, Victor Hugo may be right with his saying that "Nothing is as strong as an idea whose time has come".

\section{Conclusions}

The issues discussed above should help to show the complex and multi-layered picture of the ethical debate on the use of hESC. We do not suggest one single solution, but advocate tolerance, the support of pluralism and the acceptance of standards changing over time. Not only science develops rapidly, but also the society around. From this, we could learn that static positions may not be the ideal positions in an ethical debate. A static deadlock often leads to a debate on the debate itself, instead of a focus on solving problems and finding a common platform. It would be useful to acknowledge that one will always need advocates defending life and human dignity as well as advocates for the promotion of science. There will always be a duty of healing, just as well as a duty to examine in each case whether the means justify the goals. A basic acceptance of this situation can lead to a new form of honesty. This would imply that all parties seek to understand counterarguments, seek to be as informed as possible about scientific, cultural and ethical fundamentals, and all parties use arguments for the sake of the quality of the argument instead of employing exaggerations, rhetoric tricks, and accusations of the opponent or unnecessary distractions from the facts of the matter. After all, it is the debate itself that is important for evolution of ethical standpoints, and taking care of having a sound debate is the first and foremost step towards broadly acceptable ethical standards.

\section{References}

Baharvand, H., Ashtiani, S. K., Valojerdi, M. R. et al. (2004). Establishment and in vitro differentiation of a new embryonic stem cell line from human blastocyst. Differentiation 72 (5), 224-229.

Baker, M. (2005). Stem cell therapy or snake oil? Nat. Biotechnol. 23(12), 1467-1469.

Baker, M. (2007). Funding crunch forces stem cell company to abandon therapies. Nat. Biotechnol. 25(9), 951-952.

Baker, M. (2008). Embryonic stem-cell trial put on hold. Nature Reports Stem Cells online, http://www.nature.com/ news/2008/080519/full/news.2008.842. html

Balls, M., Coecke, S., Bowe, G. et al. (2006). The Importance of Good Cell Culture Practice (GCCP). ALTEX 23 Suppl., 270-273.

Björklund, A., Dunnett, S. B., Brundin, P. et al. (2003). Neural transplantation for the treatment of Parkinson's disease. Lancet Neurol. 2(7), 437-445.

Bongso, A., Fong, C. Y., Ng, S. C., Ratnam, S. (1994). Human embryonic behavior in a sequential human oviductendometrial coculture system. Fertil. Steril. 61(5), 976-978.

Breitbach, M., Bostani, T., Roell, W. et al. (2007). Potential risks of bone marrow cell transplantation into infarcted hearts. Blood 110(4), 1362-1369.

Bremer, S., Hartung, T. (2004). The use of embryonic stem cells for regulatory developmental toxicity testing in vitro - the current status of test development. Curr. Pharm. Des. 10(22), 2733-2747.

Broxmeyer, H. E. (2005). Biology of cord blood cells and future prospects for enhanced clinical benefit. Cytotherapy 7(3), 209-218.

Buesen, R., Visan, A., Genschow, E. et al. (2004). Trends in improving the embryonic stem cell test (EST): an overview. ALTEX 21(1), 15-22.
Chung, Y., Klimanskaya, I., Becker, S. et al. (2008). Human embryonic stem cell lines generated without embryo destruction. Cell Stem Cell 2(2), 113-117

Chung, Y., Klimanskaya, I., Becker, S. et al. (2006). Embryonic and extraembryonic stem cell lines derived from single mouse blastomeres. Nature 439(7073), 216-219.

Crook, J., Peura, T. T., Kravets, L. et al. (2008). The generation of six clinicalgrade human embryonic stem cell lines. Cell Stem Cell 1(5), 490-494.

Cyranoski, D. (2008). Stem cells: 5 things to know before jumping on the iPS bandwagon. Nature 452(7186), 406-408.

French, A. J., Adams, C. A., Anderson, L. S. et al. (2008). Development of human cloned blastocysts following somatic cell nuclear transfer with adult fibroblasts. Stem Cells 26(2), 485-493.

Gstraunthaler, G. (2006). Standardisation in Cell and Tissue Culture - The Need for Specific GLP Guidelines in the Cell Culture Laboratory (Good Cell Culture Practice - GCCP). ALTEX 23 Suppl., 274-277.

Guan, K., Schmidt, M. M., Ding, Q. et al. (1999). Embryonic Stem Cells in vitro - Prospects for Cell and Developmental Biology, Embryotoxicology and Cell Therapy. ALTEX 16(3), 135-141.

Guenin, L. M. (2005). A proposed stem cell research policy. Stem Cells 23, 1023-1027.

Hall, V. J., Li, J. Y., Brundin, P. (2007). Restorative cell therapy for Parkinson's disease: a quest for the perfect cell. Semin Cell Dev. Biol. 18(6), 859-869.

Hanna, J., Markoulaki, S., Schorderet, P. et al. (2008). Direct reprogramming of terminally differentiated mature B lymphocytes to pluripotency. Cell 133(2), 250-264

Hanna, J., Wernig, M., Markoulaki, S. et al. (2007). Treatment of sickle cell anemia mouse model with iPS cells generated from autologous skin. Science 318(5858), 1920-1923.

Hansson, M. G., Helgesson, G., Wessman, R., Jaenisch, R. (2007). Commentary: isolated stem cells - patentable as cultural artifacts? Stem Cells 25(6), 1507 1510 .

Hartung, T. (2001). Three Rs potential in the development and quality control of 
pharmaceuticals. ALTEX 18 Suppl. 1, 3-13.

Hartung, T. (2007a). Food for thought... on validation. ALTEX 24, 67-73.

Hartung, T. (2007b). Food for thought... on cell culture. ALTEX 24, 143-147.

Hartung, T. (2008). Food for thought... on animal tests. ALTEX 25, 3-10.

Hartung, T., Leist, M. (2008). Food for thought... on the evolution of toxicology and phasing out of animal testing. ALTEX 25, 91-97.

Hentze, H., Graichen, R., Colman, A. (2007). Cell therapy and the safety of embryonic stem cell-derived grafts. Trends Biotechnol.25(1), 24-32.

Johnson, M. H. (2008). Human ES cells and a blastocyst from one embryo: exciting science but conflicting ethics? Cell Stem Cell 2(2), 103-104.

Klemm, M., Schrattenholz, A. (2004). Neurotoxicity of active compounds - establishment of hESC-lines and proteomics technologies for human embryo- and neurotoxicity screening and biomarker identification. ALTEX 21 Suppl. 3, 4148.

Klimanskaya, I., Chung, Y., Becker, S. et al. (2006) Human embryonic stem cell lines derived from single blastomeres. Nature 444(7118), 481-485.

Kolossov, E., Bostani, T., Roell, W. et al. (2006). Engraftment of engineered ES cell-derived cardiomyocytes but not BM cells restores contractile function to the infarcted myocardium. J. Exp. Med. 203(10), 2315-2327.

Kuhn, T. S. (1970). The Structure of Scientific Revolutions, 2nd. ed., p. 206. Chicago: Univ. of Chicago Pr.

Leist, M. (2006). What can a chair on alternatives to animal experimentation effectuate? ALTEX 23, 211-213.

Leist, M., Hartung, T., Nicotera, P. (2008a). The dawning of a new age of toxicology. ALTEX 25, 103-114.

Leist, M., Kadereit, S., Schildknecht, S. (2008b). Food for thought... on the real success of 3R approaches. ALTEX 25, 17-24.

Lerou, P. H., Yabuuchi, A., Huo, H. et al. (2008a). Derivation and maintenance of human embryonic stem cells from poorquality in vitro fertilization embryos. Nat. Protoc. 3(5), 923-933.

Lerou, P. H., Yabuuchi, A., Huo, H. et al. (2008b). Human embryonic stem cell derivation from poor-quality embryos. Nat. Biotechnol. 26(2), 212-214.

Li, J. Y., Englund, E., Holton, J. L. et al. (2008). Lewy bodies in grafted neurons in subjects with Parkinson's disease suggest host-to-graft disease propagation. Nat. Med. 14(5), 501-503.

Lowry, W. E., Richter, L., Yachechko, R. et al. (2008). Generation of human induced pluripotent stem cells from dermal fibroblasts. Proc. Natl. Acad. Sci. USA 105(8), 2883-2888.

Luttun, A., Verfaillie, C. M. (2006). A perspective on stem cells as a tool for in vitro testing. ALTEX 23 Suppl., 388-392.

Maio, G. (2006). Cloning in the media and popular culture. An analysis of German documentaries reveals beliefs and prejudices that are common elsewhere. EMBO Rep. 7(3), 241-245.

MBBNET (2008). http://mbbnet.umn.edu/ scmap.html

McLaren, A. (2007). A scientist's view of the ethics of human embryonic stem cell research. Cell Stem Cell 1(1), 23-26.

Meissner, A., Jaenisch, R. (2006). Generation of nuclear transfer-derived pluripotent ES cells from cloned Cdx2-deficient blastocysts. Nature 439(7073), 212215.

Moore, T., Ball, M. (2004). Kaguya, the first parthenogenetic mammal - engineering triumph or lottery winner? Reproduction 128(1), 1-3.

Nakagawa, M., Koyanagi, M., Tanabe, K. et al. (2008). Generation of induced pluripotent stem cells without Myc from mouse and human fibroblasts. Nat. Biotechnol. 26(1), 101-106.

Nygren, J. M., Jovinge, S., Breitbach, M. et al. (2004). Bone marrow-derived hematopoietic cells generate cardiomyocytes at a low frequency through cell fusion, but not transdifferentiation. Nat. Med. 10(5), 494-501.

Pellizzer, C., Bremer, S., Hartung, T. (2005). Developmental toxicity testing from animal towards embryonic stem cells. ALTEX 22(2), 47-57.

Pickering, S. J., Minger, S. L., Patel, M. et al. (2005). Generation of a human embryonic stem cell line encoding the cystic fibrosis mutation deltaF508, using preimplantation genetic diagnosis. Reprod. Biomed. Online 10(3), 390-397.
Plomer, A., Taymor, K. S., Scott, C. T. (2008). Challenges to human embryonic stem cell patents. Cell Stem Cell 2(1), 13-17.

Popper, Karl R. (1965). .The logic of scientific discovery, 4th ed., p. 479. London: Verlag Hutchinson.

Revazova E. S., Turovets N. A., Kochetkova O. D. et al. (2007). Patient-specific stem cell lines derived from human parthenogenetic blastocysts. Cloning Stem Cells 9, 432-449.

Revazova, E. S., Turovets, N. A., Kochetkova, O. D. et al. (2008). HLA homozygous stem cell lines derived from human parthenogenetic blastocysts. Cloning Stem Cells 10(1), 11-24.

Revel, A., Safran, A., Laufer, N. et al. (2004). Twin delivery following 12 years of human embryo cryopreservation: case report. Hum. Reprod. 19(2), 328-329.

Revel, M. (2003). Human reproductive cloning, embryo stem cells and germline gene intervention: an Israeli perspective. Med. Law 22(4), 701-732.

Rispin, A. S., Stitzel, K. (2006). Ensuring quality of in vitro alternative test methods. ALTEX 23 Suppl., 278-283.

Robertson, J. A. (2001). Human embryonic stem cell research: ethical and legal issues. Nat. Rev. Genet. 2(1), 74-78.

Sangiorgi, E., Capecchi, M. R. (2008). Bmil is expressed in vivo in intestinal stem cells. Nature Genetics 40(7), 915920.

SC4SM (2008). http://www.sc4sm.org/

Schoemans, H., Theunissen, K., Maertens, J. et al. (2006). Adult umbilical cord blood transplantation: a comprehensive review. Bone Marrow Transplant 38(2), 83-93.

Schrattenholz, A., Klemm, M. (2007). Neuronal cell culture from human embryonic stem cells as in vitro model for neuroprotection. ALTEX 24(1), 9-15.

Schuklenk, U. (2008). How not to win an ethical argument: embryo stem cell research revisited. Bioethics 22(2), ii-iii.

Seiler, A., Buesen, R., Hayess, K. et al. (2006). Current status of the embryonic stem cell test: the use of recent advances in the field of stem cell technology and gene expression analysis. ALTEX 23 Suppl., 393-399.

Seiler, A., Visan, A., Pohl, I. et al. (2002). 
Etablierung molekularer Endpunkte zur Weiterentwicklung des Embryonalen Stammzelltests (EST) mit embryonalen Stammzellen der Maus (Zelllinie D3) [Improving the embryonic stem cell test (EST) by establishing molecular endpoints of tissue specific development using murine embryonic stem cells (D3 cells)]. ALTEX 19 Suppl. 1, 55-63.

Singer, Peter (1993). Practical Ethics, 2nd. ed. Cambridge: Cambridge University Press. (Praktische Ethik, 2. Aufl., 1993, Stuttgart: Reklam.)

Smith, S., Neaves, W., Teitelbaum, S. (2006). Adult stem cell treatments for diseases? Science 313(5786), 439.

Solter, D. (2006). From teratocarcinomas to embryonic stem cells and beyond: a history of embryonic stem cell research. Nat. Rev. Genet. 7(4), 319-327.

Strübing, C., Wobus, A. M., Hescheler, J. (1995). Etablierung eines in vitro Modellsystems zur Differenzierung synaptisch verknüpfter Nervenzellen aus pluripotenten embryonalen Stammzellen der Maus [Establishment of an in vitro model system for the differentiation of synaptically coupled neurons from mouse embryonic stem cells]. $A L$ TEX 12(3), 129-137.

Takahashi, K., Tanabe, K., Ohnuki, M. et al. (2007). Induction of pluripotent stem cells from adult human fibroblasts by defined factors. Cell 131(5), 861-872.

Takahashi, K., Yamanaka, S. (2006). Induction of pluripotent stem cells from mouse embryonic and adult fibroblast cultures by defined factors. Cell 126(4), 663-676.

Tannert, C. (2006). Thou shalt not clone. An ethical argument against the reproductive cloning of humans. EMBO Rep. 7(3), 238-240.
Teramura, T., Takehara, T., Kishi, N. et al. (2007). A mouse and embryonic stem cell derived from a single embryo. Cloning Stem Cells 9(4), 485-494.

Thomas, C. (2006). Preimplantation genetic diagnosis: development and regulation. Med. Law 25(2), 365-378.

Thomson, J. A., Itskovitz-Eldor, J., Shapiro, S. S. et al. (1998). Embryonic stem cell lines derived from human blastocysts. Science 282(5391), 1145-1147.

Trounson, A., Klein, R., Murphy, R. (2008). Stem cell research in California: the game is on. Cell 132(4), 522-524.

UKTI (2005). http://www.chrismason. com/industry_library/assets/UKTI\%20 Stem\%20Cell\%20Res.pdf

Vogel, G. (2005). Ready or not? Human ES cells head toward the clinic. Science 308(5728), 1534-1538.

Wellbery, C. (2000). Emergency contraception. Arch. Fam. Med. 9(7), 642646.

Wernig, M., Meissner, A., Foreman, R. et al. (2007). In vitro reprogramming of fibroblasts into a pluripotent ES-cell-like state. Nature 448(7151), 318-324.

Whitlow, S., Bürgin, H., Clemann, N. (2007). The embryonic stem cell test for the early selection of pharmaceutical compounds. ALTEX 24(1), 3-7.

Wobus, A. M., Hescheler, J. (1992). Entwicklung eines in vitro-Herzzell-Modells für embryotoxikologische und pharmakologische Studien [Development of an in vitro cardiomyocytes cell model for embryotoxicological and pharmacological studies]. ALTEX 9(2), 29-42.

Xu, X. Q., Zweigerdt, R., Soo, S. Y. et al. (2008). Highly enriched cardiomyocytes from human embryonic stem cells. $C y$ totherapy, (in press).
Yu, J., Vodyanik, M. A., Smuga-Otto, K. et al. (2007). Induced pluripotent stem cell lines derived from human somatic cells. Science 318(5858), 1917-1920.

Zollner, U.,Zollner, K.-P., Steck, T. (2003). Blastozystenkultur unter den Bedingungen des Deutschen Embryonenschutzgesetzes. Gynäkologische Endokrinologie 1, 176-182.

Zoloth, L. (2002). Stem cell research: a target article collection: Part I - Jordan's banks, a view from the first years of human embryonic stem cell research. Am. J. Bioeth. 2(1), 3-11.

\section{Acknowledgement}

We gratefully acknowledge the valuable ideas, information and food for thought received from F. Gruber and many of our colleagues during countless good discussions. The research leading to these results has received funding from the European Community's Seventh Framework Programme (FP7/2007-2013; ESNATS project), the Land Baden-Württemberg and the Doerenkamp-Zbinden Foundation.

\section{Correspondence to}

Prof. Dr. Marcel Leist

Doerenkamp-Zbinden Chair for alternative in vitro methods Faculty of Natural Sciences and Mathematics

University of Konstanz

Box M657

78457 Konstanz

Germany

phone: +49-7531 885037

fax: +49-7531885039

e-mail: marcel.leist@uni-konstanz.de 